Tectonophysics

December 2016, Volume 692, Part B, Pages 98-119

http://dx.doi.org/10.1016/..tecto.2016.02.022

http://archimer.ifremer.fr/doc/00316/42686/

(c) 2016 Elsevier B.V. All rights reserved.

\title{
Geodynamics of the South China Sea
}

\author{
Sibuet Jean-Claude ${ }^{1,3,{ }^{*}}$, Yeh Yi-Ching ${ }^{2}$, Lee Chao-Shing ${ }^{3}$
}

${ }^{1}$ Ifremer Centre de Brest, BP 70, 29280 Plouzané Cedex, France

2 Taiwan Ocean Research Institute, 219, Sec. 1 Dongfang Rd., Qieding Dist., Kaohsiung 852, Taiwan

${ }^{3}$ Institute of Applied Geophysics, National Taiwan Ocean University, 2 Pei-Ning Road, Keelung, 202, Taiwan

*Corresponding author : Jean-Claude Sibuet, email address : jean.claude.sibuet@gmail.com

yiching.yeh@gmail.com ; leecs@mail.ntou.edu.tw

\begin{abstract}
:
The beginning of seafloor spreading in the South China Sea (SCS) is now established from IODP drilling Leg 349 at $33 \mathrm{Ma}$. Chron 12 (32 Ma) is the oldest chron identified in the SCS. The nature of the crust of the northeastern part of the SCS located north of chron C12, where chrons 15 to 17 were previously identified, is not oceanic but thinned continental crust intruded by volcanic elongated features emplaced 17-22 Ma ago. Based on magnetic anomalies identifications, the end of the SCS spreading could be either 15.5, 20.5 Ma (Briais et al., 1993; Barckhausen et al., 2014) or something else. However, as post-spreading magmatic activity ( 13-3.5 Ma) largely masks the spreading fabric in particular near the axis of the east sub-basin, published locations of the axial magnetic anomaly (extinct spreading axis) and spreading rates are not reliable. A contoured map of the extremely dense set of magnetic data shows that a few magnetic lineations belonging to the magnetic seafloor spreading fabric are still preserved and parallel to the $\mathrm{N} 055^{\circ}$ bathymetric seafloor spreading trends identified on swathbathymetric maps in the central part of the SCS, suggesting the extinct ridge axis is $N 055^{\circ}$ trending with potential $\mathrm{N} 145^{\circ}$ transform faults. Based on published swath-bathymetric data, oceanic domains with different seafloor spreading lineaments have been delimited ( $\mathrm{N} 055^{\circ}, \mathrm{N} 075^{\circ}$ and $\left.\mathrm{N}^{\circ} 85^{\circ}\right)$ and provide important constraints used to propose a kinematic sketch of the SCS opening. As a consequence, the Zhongnan faults zone, located between the east and southeast sub-basins, acted as a major fracture zone system during the SCS opening, with horizontal offsets varying from $\sim 50 \mathrm{~km}$ to $\sim 140 \mathrm{~km}$.

The flow-line pattern defined from the seafloor spreading lineaments and the few identified FZs have been used to highlight conjugate segments of continental margins. During the first phases of opening of

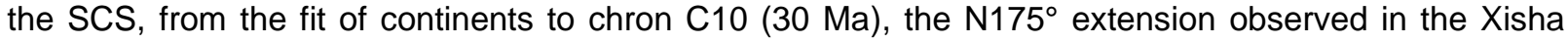
trough and eventually south of the Macclesfield bank extends to the Qui Nhon ridge, located along the eastern margin of Vietnam, in the southward prolongation of the Red River Fault system. Normal faults curve toward the south with a horsetail geometry interpreted as evidence for a few tens of $\mathrm{km}$ of dextral motion along the Qui Nhon ridge. Since chron 10 and until the end of SCS opening, the plate boundary located between the southern South China Sea (SSCS) and EU plates jumped westward several times from the location of the Ulugan fault near Palawan to the western limit of the southwest basin, explaining the progressive formation of the SCS from east to west and giving the characteristic V-shape
\end{abstract}


of the SCS. The opening of the whole SCS is linked and occurred simultaneously with the northward subduction of the proto-SCS whose suture is located south of Palawan and extends westwards in north Borneo.

\section{Highlights}

- Northeastern South China Sea crust is thinned continental crust intruded by volcanics $>$ Postspreading magmatic activity $\left(<13 \mathrm{Ma}\right.$ ) largely masks the spreading fabric $>\mathrm{N} 055^{\circ}, \mathrm{N}^{\circ} 75^{\circ}$ and $\mathrm{N} 085^{\circ}$ seafloor spreading oceanic domains are identified - Extension in Xisha trough and south of Macclesfield bank extends to Qui Nhon Ridge S South China Sea (SCS) opening is compensated by northward proto-SCS subduction

Keywords : South China Sea, gravity, magnetics, structural and tectonic analyses, kinematics 


\section{Introduction}

Even if the South China Sea (SCS) is a well-studied Tertiary marginal sea, there are a number of unsolved questions concerning its formation. For example, south of the northeastern SCS continental margin, the oldest oceanic crust was supposed to be formed since chron 17 (37.8 Ma (Hsu et al., 2004)) instead of chron 12 (32 Ma (Barckhausen et al., 2014)). New wideangle seismic reflection and refraction data will be used to discuss the oceanic or continental nature of the crust in this region and the origin of the magnetic lineations previously interpreted as seafloor spreading lineations. On the other side, at the extinct ridge axis location, the youngest crust is either younger than C5c (15.5 Ma (Briais et al., 1993)) or C6a1 (20.5 Ma (Barckhausen et al., 2014)). In addition, differences between spreading rates as well as resulting asymmetries deduced from the geometry of magnetic lineations are so large that the question to understand why is raised. We will demonstrate that the reason is due to the postspreading phase of extension associated with a large excess of volcanism, which partly masks the previous seafloor spreading fabric. New published swath-bathymetric maps of the whole SCS, the new one-minute worldwide gravity anomaly map (Sandwell et al., 2014), a compilation of magnetic data collected in the whole SCS (Ishihara and Kisimoto, 1996) and results from IODP Leg 349 drill sites (IODP Preliminary Report, 2014) will be used to unravel the SCS tectonic pattern and initial seafloor spreading fabric in order to propose a kinematic sketch of the evolution of the SCS and a satisfactory correspondence between conjugate segments of continental margins.

\section{Previous kinematic models}

Numerous Cenozoic tectonic and kinematic models have been proposed for the SCS but it remains uncertain whether the SCS experienced a single episode or multiple episodes of extension and seafloor spreading (see discussion in the IODP Preliminary Report (2014)). The opening of the east sub-basin may have predated (e.g. (Taylor and Hayes, 1983; Briais et al., 1993; Barckhausen et al., 2014; Ding et al., 2016)) (Figure 1), is synchronous (e.g. (Honza, 1995)) or have postdated (e.g. (Ru and Pigott, 1986; Yao et al., 1994)) the opening of the southwest sub-basin. The greater average water depth of the southwest sub-basin compared to the east sub-basin has been interpreted to imply relatively older crustal ages, which conflicts with younger ages inferred from the highest heat flow values (Ru and Pigott, 1986), with 
similar ages of magnetic lineations in the two east and southwest sub-basins (Briais et al., 1993; Barckhausen et al., 2014) and with similar drilling results at IODP sites U1431 and U1433 (Figure 1). Presently, there is no clear available explanation for this difference in depth between the two sub-basins. All models consider sharp geological and geophysical contrasts between the east and southwest sub-basins, emphasizing the important role of the Zhongnan faults zone (Figure 1). Two models of slow propagation of the SCS spreading center, one with opening gradually propagating toward the northeast (Chung et al., 1994) and the other toward the southwest (Zhou et al., 1995) were also proposed. The multitude of tectonic and kinematic models suggests the SCS is a complex marginal oceanic basin still not yet understood even if a considerable amount of geological and geophysical data have been acquired.

\section{Nature of the crust in the northeastern South China Sea and age of onset of seafloor spreading}

Magnetic data acquired in the northernmost SCS show the existence of $\mathrm{N} 080^{\circ}$ trending magnetic lineations interpreted as chrons C17 to C15 (Late Eocene, 37 to $35 \mathrm{Ma}$ ), with a spreading rate of $88 \mathrm{~mm} / \mathrm{yr}$ (Hsu et al., 2004) (Figure 2). Chrons C17 to C15 are located inside the domain bounded by AA', BB' and the Luzon-Ryukyu transform plate boundary (LRTPB) (Sibuet et al., 2002). Two wide-angle and refraction seismic lines were shot in this domain (OBS2002 and MGL905-20 lines). Figure 3 shows P-wave velocity profiles below the top of the basement for each OBS of Profile OBS2001 (Wang et al., 2002; Yeh et al., 2010), the mean P-wave velocity profile for Profile MGL905-20 (Lester et al., 2014) and the MCS stack velocities that we have determined during the seismic processing of lines MGL0905-3, 4, 5, 10, 20, 25A for their portions located inside the domain bounded by AA', BB' and LRTPB. The results are compared with the envelopes of velocities for the 59-170 Ma oceanic crust (White et al., 1992), with exhumed mantle on the west Iberia margin (Bullock and Minshull, 2005) and with the average velocity curve for extended continental crust (Christensen and Mooney, 1995) (Figure 3). As usual, the results are not constrained in the upper 2-3 km of basement (Sibuet and Tucholke, 2012), where velocities of serpentinized peridotite, old oceanic crust and thinned continental crust are similar. Below this depth, velocities belong to the field of thinned continental crust. Consequently, as the upper $2-3 \mathrm{~km}$ of crust consist of tilted continental faults blocks at least on some portions of seismic profiles, the whole crust bounded by AA', BB' and the LRTPB is underlined by thinned continental crust (Figure 4), not by oceanic crust. 
The MCS profile MGL0905-20, located in Figure 2, displays several features suggesting that the crust is thinned continental crust intruded by post-rift volcanism (Figure 5): continental tilted fault bocks are well-defined from the continental shelf to CMP 9000; high lower crustal velocities might correspond to underplating created during rifting as shown on other passive continental margins.

Figures 6 and 7 display MCS profiles MCS689-1 and MGL0905-10 located in Figure 2 with our new interpretation. On the post-stack time migration MCS profile MGL0905-10, underplating is present along the whole profile except northeast of CMP20000. The two profiles cut across the magnetic lineations previously interpreted as chrons 15 to 17 (Hsu et al., 2004). These magnetic lineations are associated with intruded volcanic bodies through the thinned continental crust, which have uplifted sediments up to the T2 unconformity (Figures 6 and 7). This T2 unconformity was correlated with a jump of the Ryukyu subduction zone from the location of the LRTPB feature to $126^{\circ} \mathrm{E}$ longitude (east of present-day Taiwan) (Sibuet et al., 2004). Subduction ceased at that time in the northeastern SCS as attested by the subsidence curves of the west Taiwan basins wells. The significant change in the slope of subsidence curves in wells on the continental shelf west of Taiwan at 17-18 Ma, was interpreted as the transition between the end of the rifting period in the west Taiwan backarc basins and the beginning of the thermal subsidence, event associated with the removal of the Ryukyu subduction zone in this area (Sibuet and Hsu, 2004). Several dredges on a volcanic seamount $\left(21^{\circ} 10^{\prime} \mathrm{N} ; 119^{\circ} 12^{\prime} \mathrm{E}\right)$ intruded through the thinned continental crust (Yeh et al., 2012) give an Ar/Ar age of $22 \mathrm{Ma}$ (Hsu et al., 2004). Thus, the age of emplacement of volcanic ridges intruded through the thinned continental crust occurred between 22 to $17 \mathrm{Ma}$. On the post-stack time migration MCS profile MGL0905-10, sills are observed between unconformities T1 and $\mathrm{T} 2$, attesting that some form of post-spreading volcanism may have occurred but we have no constraint on their ages of emplacement.

To conclude, we confirm that the nature of the crust of the northeastern part of the SCS located north of chron C12 (32 Ma) is not oceanic but thinned continental crust. On the base of a refraction profile coincident with MCS Profile MGL905-20 and a series of deep MCS profiles acquired during the TAIGER (TAiwan Integrated GEodynamics Research) program, this was already proposed by Eakin et al. (2014), Lester et al. (2013), Lester et al. (2014), McIntosh et al. (2013) and McIntosh et al. (2014), who provided evidence that the crust flooring the northeastern SCS south of Taiwan consists of $\sim 10-15 \mathrm{~km}$-thick extended to hyperextended continental crust, interspersed with volcanic bodies. The end of the rifting 
episode is older than 32 Ma probably $\sim 33 \mathrm{Ma}$ as shown at the location of IODP Site U1435 where a sharp unconformity is dated $\sim 33 \mathrm{Ma}$, with deep marine facies above sandy lithologies of shallow marine deltaic or coastal facies (IODP Preliminary Report, 2014). The postspreading volcanism dated there 17-22 Ma takes the form of elongated intrusions through the thinned continental crust but also the form of sills emplaced in the sedimentary column between unconformities $\mathrm{T} 1$ and $\mathrm{T} 2$.

\section{Age of cessation of seafloor spreading activity in the South China Sea}

In 1993, Briais et al. (1993) presented the interpretation of a set of closely spaced marine magnetic profiles located in the east and southwest sub-basinssub-. Seafloor spreading was found to be asymmetric and they suggested two ridge jumps, one located north of Macclesfield Bank at chron C10 and one in the northern part of the east sub-basin occurring just after chron C7 (25 Ma), with two magnetic lineations C7 in the northern part of the east sub-basin and magnetic lineations C6b and C8 juxtaposed in the south. Spreading stops synchronously along the seafloor spreading axis in the east and southwest sub-basins separated by the Zhongnan faults zone at about 15.5 Ma, just after chron C5c (16 Ma) (Figure 1a). Later, Barckhausen and Roeser (2004) and Barckhausen et al. (2014) acquired a series of magnetic profiles, paying great attention to magnetic corrections, especially because the SCS is close to the equator. They modeled magnetic lineations by maintaining spreading rates constant over long periods of time and they identified a ridge jump in the northern part of the east sub-basin at anomaly C7 (25 Ma), leaving magnetic lineations C8 and C9 in the northern part of the east sub-basin (Figure 1b). The formation of oceanic crust started in their model at chron C12 (32 Ma) in the east subbasin, later in the southwest sub-basin and ended at the same time (chron C6a1, 20.5 Ma) in the east and southwest sub-basins. They find indications for a stepwise propagation of the seafloor spreading from northeast to southwest along corridors bounded by major fracture zones, which are not always parallel. Li et al. (2015), using several deep-tow magnetic profiles acquired across the east and southwest sub-basins, basically constrain their forward modeling by microfossil age constraints at/or near the sediment-basement interface of four IODP Leg 349 holes used as referencing points: $33 \mathrm{Ma}$ (chron C12n) as the earliest seafloor spreading near Site U1435, 16.7-17.5 Ma (C5bn) at Site U1431 close to the east sub-basin extinct ridge, 18-21 Ma at Site U1433 located $50 \mathrm{~km}$ away from the same extinct ridge in the southwest sub-basin and 12-18 Ma at Site U1434 located $25 \mathrm{~km}$ away from the southwest basin extinct ridge, without proposing their own interpretation but seeming to support the Briais et al. (1993) 
modeling in the southwest sub-basin (C5bn). Thus, from their referencing points they attributed the earliest and latest magnetic anomalies in the east sub-basin to C12n and C5bn respectively. They also identified the ridge jump at C6cr, at the same place or very close to the ridge jump identified at chron C7 by Briais et al. (1993) and Barckhausen et al. (2014).

The common points between the three above modelings and the preliminary drilling results from IODP Leg 349 (IODP Preliminary Report, 2014) are the following: in the east subbasin, the onset of seafloor spreading occurred 33 Ma ago (chron C12n). Seafloor spreading aborted between Macclesfield Bank and the south China continental margin leaving an extinct ridge in the axis of the small basin located north of Macclesfield Bank (chron C10?). A ridge jump occurred in the east sub-basin somewhere between chrons C7 and C6cr, leaving, depending of the three types of modeling, a variable portion of previously formed oceanic crust in the northern part of the east sub-basin.

The main divergent point between the three modelings is the age of the latest identified magnetic lineations (younger than $\mathrm{C} 5 \mathrm{c}, \mathrm{C} 5 \mathrm{~b}$ or $\mathrm{C} 6 \mathrm{a} 1$ ). This is mostly due to the presence of a strong post-spreading volcanism, which hides the spreading fabric in particular in the potential region of the extinct spreading axis and complicates the identification of magnetic lineations. The post-spreading volcanism has been dated from volcaniclastic breccia and sandstone recovered at Site U1431 (located in Figure 1) as late middle Miocene to early late Miocene ( 8-13 Ma), suggesting at least a 5 Ma duration of seamount volcanism after the cessation of seafloor spreading (IODP Preliminary Report, 2014), which may be extended to a $10 \mathrm{Ma}$ duration as some of the numerous datations of post-spreading volcanoes may give ages as young as 3.5 Ma (Tu et al., 1992) for the post-rift volcanism. This post-spreading activity has consequences for magnetic studies: Briais et al. (1993) introduced a minor ridge jump in the vicinity of chrons $5 \mathrm{c}-5 \mathrm{~d}$ and identified the post-spreading chain of seamounts in the east subbasin as the location of the fossil spreading center; Barckhausen et al. (2014) did about the same reasoning with the E-W portion of the post-spreading chain of seamounts identified as the extinct spreading ridge axis but without minor late ridge jump. In both cases, an inappropriate identification of the central magnetic lineation disrupts the identification of older lineations and leads to highly variable spreading rates in both the east and southwest sub-basins. A detailed inspection of swath-bathymetric data (Barckhausen et al., 2014) and magnetic deep-tow and surface data ( $\mathrm{Li}$ and al., 2015) in the area located south of IODP Site 1431 shows that the extinct spreading axis is located about $60 \mathrm{~km}$ south of IODP Site 1431 instead of $20 \mathrm{~km}$ (IODP Preliminary Report, 2014). As an example, with full spreading rates of 40 and $80 \mathrm{~mm} / \mathrm{yr}$ during 
the last stage of opening of the east sub-basin for Briais et al. (1993) and Barckhausen et al. (2014) respectively, the formation of oceanic crust at Site U1431 is older than the age of the extinct ridge axis of $3 \mathrm{Ma}$ or $1.5 \mathrm{Ma}$, respectively, if we assumed that the extinct ridge axis is located $60 \mathrm{~km}$ south of Site U1431.

Two massive lava-flow series, separated by a 10-m thick sequence of lower Miocene yellowish brown claystone and claystone breccia, were drilled at IODP Site U1431. The intercalated claystone layer is barren of in situ calcareous microfossils but radiolarian biostratigraphy indicates that this sedimentary layer, corresponding to the radiolarian zone RN4, is early Miocene in age ( 16.7-17.5 Ma). The petrology and geochemistry of igneous basement rocks suggest a MORB composition for the two lava-flow series (Tejada et al., 2014) but it is impossible to tell if the two volcanic series are distinct sills or a sill overlying typical oceanic crust of MORB composition as suggested by the IODP Leg 349 scientific team (IODP Preliminary Report, 2014). Ar/Ar datations of igneous rocks at site U1431 (Koppers, 2014) give 14. 97 +/- 0.17 Ma for the upper lava-flow (core 41R) and 15.20 +/- 0.19 Ma for the lower basaltic unit (core 47R). The Ar/Ar age of the lower basaltic unit is slightly younger than the age of the overlying sedimentary layer. The resulting interpretation is either the upper basaltic unit is a sill and the lower unit the massive basalt of the typical oceanic crust or the lower basaltic unit is also a sill intruded between layers of already deposited sediments. Note that the N-S oriented MCS profile 973SCSIO01e (IODP Proposal 735-CCP, 2012) displays numerous intra-basement seismic reflections, which suggest that the basement might consist of numerous sills intercalated with sediments. The age at the ridge axis located about $60 \mathrm{~km}$ south of IODP Site U1431 would be 12.2 Ma (with spreading rates of Briais et al. (1993)), much younger than the 15.5 Ma age given by Briais et al. and 13.7 Ma (with spreading rates of Barckhausen et al. (2014)), still far from the 20.5 Ma given by Barckhausen et al. (2014).

Pillow and massive lava flow series were recovered at Sites U1433 and U1434 located about $50 \mathrm{~km}$ and $15 \mathrm{~km}$ respectively from the fossil spreading axis of the southwest sub-basin. $\mathrm{Ar} / \mathrm{Ar}$ datations of igneous rocks at site U1433 (Koppers, 2014) give 17.29 +/- 0.18 Ma for the upper pillow lava-flow (core 66R) and 17.31 +/- 0.25 Ma for the lower massive lava flow series (core 47R). At site U1434, an age of 16.3 Ma was found in the pillow lava flow debris of core 12R. With full spreading rates of 40 or $80 \mathrm{~mm} / \mathrm{yr}$ during the last stage of opening of the southwest sub-basin for Briais et al. (1993) and Barckhausen et al. (2014) respectively, the formation of oceanic crust at Site U1433 located $50 \mathrm{~km}$ away from the fossil spreading axis is older than the age of the extinct ridge axis of $2.5 \mathrm{Ma}$ or $1.25 \mathrm{Ma}$, respectively. The age of 
cessation of sea-floor spreading in the southwest sub-basin would be 14.8 Ma with spreading rates of Briais et al. (1993) and 16.05 Ma with spreading rates of Barckhausen et al. (2014). With the ages obtained on basalt debris at Site U1434, the age of cessation of sea-floor spreading in the southwest sub-basin would be 15.5 Ma with spreading rates of Briais et al. (1993) and 15.9 Ma with spreading rates of Barckhausen et al. (2014).

Ages of cessation of sea-floor spreading in the east and southwest sub-basins would be 12.2 and 15.5 Ma respectively with spreading rates of Briais et al. (1993) and 13.7 and 15.9 Ma respectively with spreading rates of Barckhausen et al. (2014). If true oceanic crust was drilled, the outcomes of these simple calculations would be: a) spreading ceased about $3 \mathrm{Ma}$ later in the southwest sub-basin compared with the east sub-basin and b) Spreading ceased at 12-13 Ma in the east sub-basin. Consequently, there are still no definitive arguments concerning the age of the cessation of seafloor spreading activity in the SCS. Ages based on the three magnetic modelings for the end of seafloor spreading in the SCS, (younger than C5c (15.5 Ma) (Briais et al., 1993), C5b (15 Ma) (Li and al., 2015) and C6a1 (20.5 Ma) (Barckhausen et al., 2014)) are older than ages extrapolated from the Ar/Ar datations, suggesting that either drilling at Site U1431 ended in a sill emplaced during post-spreading activity, which is our favorite hypothesis or that the heating due to the nearby post-spreading volcanism may have disturbed the Ar/Ar dating procedure. In any case, these results do not seem to be consistent.

\section{New data to constrain kinematic reconstructions}

Numerous geophysical data are now available in the SCS. For example, even if all the swath-bathymetric data acquired by the SCS surrounding countries for their "extension of the continental shelf" programs or by foreign countries are not publicly available in digital form, most of them are available in the grey literature or published as analogical detailed maps extremely useful to identify seafloor spreading trends and FZs (e.g. (Li, 2011; Li et al., 2011; Li et al., 2012; Barckhausen et al., 2014)). The one-minute free-air gravity anomaly map (Sandwell et al., 2014) available since summer 2014 is also extremely useful to identify a few kilometers or a few tens of kilometers long crustal features better outlined in the gravity field than in the swath-bathymetric data when these features are buried beneath sediments. Finally, the contoured magnetic anomaly map (Ishihara and Kisimoto, 1996) is also a crucial document as it displays the continuity of marine magnetic lineations in the SCS.

\subsection{South China Sea structural pattern}


Figure 8 shows a close-up of swath-bathymetry, free-air gravity and magnetic anomalies of a portion of the east and southwest sub-basins separated by the Zhongnan faults zone and

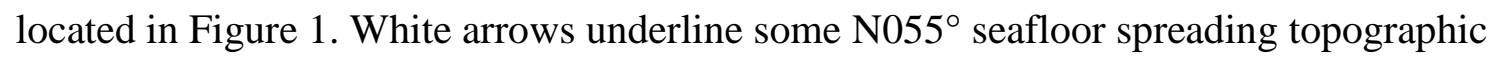
features located in the central part of the east and southwest sub-basins (Figure 8a). Outside this area, seafloor spreading topographic features are $\mathrm{N} 075^{\circ}$ oriented, even $\mathrm{N} 085^{\circ}$ close to the northern and southern extremities of the detailed maps. The large seamounts correspond to post-rift volcanism. Seafloor spreading features located inside ovals with white dashed lines (Figure 8a), are of minor size and do not seem to be uplifted. Their borders are linear and trend perpendicularly to seafloor spreading lineaments. Ovals 1 and 2 are located on each side of the Zhongnan faults zone, in the most recent oceanic domains of the east and southwest sub-basins. In each oval, the seafloor spreading features abruptly stop along a linear trend, which is perpendicular to seafloor spreading features. These trends are fracture zones of the spreading fabric. Similarly oval 3 displays the same kind of features but seafloor spreading features trend $\sim \mathrm{E}-\mathrm{W}$ and the fracture zone trend $\sim \mathrm{N}-\mathrm{S}$, showing that this oceanic domain belongs to the oldest

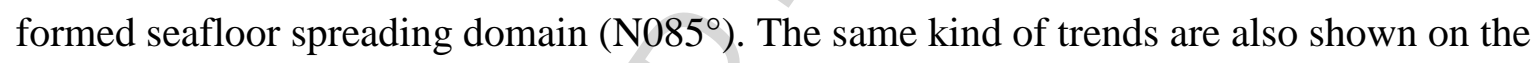
free-air gravity map (Sandwell et al., 2014) (Figure 8b).

The contoured magnetic anomalies map (Figure 8c) shows the lateral continuity of magnetic lineations, which is largely disrupted by the post-spreading volcanism and by the Zhongnan faults zone. However, in the central part of the east sub-basin, we not only evidence the seafloor spreading grain (black arrows showing the $\mathrm{N} 055^{\circ}$ seafloor spreading features) but that the main grain is $\mathrm{N} 055^{\circ}$ oriented. They are only a few E-W trends (underlined by red arrows), which correspond to post-spreading volcanic trends. Outside the area with $\mathrm{N} 055^{\circ}$ oriented features, magnetic lineations are $\mathrm{N} 075^{\circ}$ and $\mathrm{N} 085^{\circ}$ trending, consistent with seafloor spreading trends identified in Figure 8a.

Seafloor spreading lineaments have been identified by using all the different available swath-bathymetric maps (e.g. (Li, 2011; Li et al., 2011; Li et al., 2012; Barckhausen et al., 2014)) (Figure 9). These trends are mostly concentrated in the axial part of the SCS where the thickness of sediments is reduced and where the post seafloor spreading volcanism was possibly at the origin of uplifted portions of genuine oceanic crust. Clear negative magnetic trends are underlined on the contoured magnetic anomalies map (Ishihara and Kisimoto, 1996) to pinpoint the correspondence with seafloor spreading trends and give informations concerning the oldest portions of the oceanic domain where sediments hide the substratum morphology. Oceanic domains with different seafloor spreading directions have been delimited 
(Figure 9) and appear in different colors (Figure 10): light pink, light yellow and light blue correspond to $\mathrm{N} 055^{\circ}, \mathrm{N} 075^{\circ}$ and $\mathrm{N} 085^{\circ}$ seafloor spreading lineaments, respectively. The boundaries between domains of different colors are drawn with some uncertainty as these boundaries are defined in between seafloor spreading segments often separated by significant distances (Figure 9). Though not very precise, the proposed pattern is coherent from a kinematic point of view. The main observations are the following:

1) The pink domain is characterized by $\mathrm{N} 055^{\circ}$ seafloor spreading features observed in the east and southwest sub-basins. It is the most well defined domain as seafloor spreading segments are numerous compared with those in other domains (Figure 9). The width of the pink domain is about the same in the two sub-basins, supporting the idea that the SCS opening was simultaneous and ceased at the same time in the two sub-basins, in accordance with Barckhausen et al. (2014) who proposed that seafloor spreading ceased at the same time in the two sub-basins.

- The Zhongnan faults zone acted as a series of parallel fracture zones during the opening of the pink domain. Its global left-lateral horizontal offset is $\sim 50 \mathrm{~km}$.

- The westernmost part of the pink domain located west of $112^{\circ} \mathrm{E}$ decreases in width towards the west. It means that this westernmost portion of oceanic domain started to open more recently that the rest of the pink domain.

- East of $118.5^{\circ} \mathrm{E}$, the seafloor spreading axis jumped to the north as shown by swathbathymetric data and as proposed by Barckhausen et al. (2014).

2) The yellow domain is characterized by $\mathrm{N} 075^{\circ}$ seafloor spreading features observed in the east and southwest sub-basins. When the pink domain is closed, the total width of the yellow domain located east of $113.5^{\circ} \mathrm{E}$, is about the same in the two sub-basins. At the onset of the pink domain (early Miocene) the spreading axis changed direction, cutting obliquely the southwest sub-basin and unevenly the east sub-basin. It corresponds to a ridge jump both in position and direction, which is difficult to identify from magnetic data alone.

- The western part of the yellow domain located west of $113.5^{\circ} \mathrm{E}$ decreases in width towards the west and consequently started to open more recently that the rest of the yellow domain. - The Zhongnan faults zone acted as a fracture zone system during the opening of the yellow domain. Its horizontal offset $(\sim 140 \mathrm{~km})$ is larger than the one in the pink domain $(\sim 50 \mathrm{~km})$.

3) The blue domain is characterized by $\mathrm{N} 085^{\circ}$ seafloor spreading features observed in the east sub-basin and is reduced in size in the southwest sub-basin. The width of the north and south portions of blue domain in the east sub-basin is different suggesting a southward ridge 
jump occurred during the formation of the blue domain, as shown by previous magnetic modelings (Briais et al., 1993; Barckhausen et al., 2014; Li and al., 2015).

- The Zhongnan faults zone acted as a fracture zone with an horizontal offset of $\sim 140 \mathrm{~km}$ during the opening of the more recent part of the blue domain, suggesting the Zhongnan faults zone was possibly inactive at the beginning of opening of the SCS.

\subsection{Fracture zones trends and conjugate segments of continental margins}

Only a few segments of fracture zones trending $\mathrm{N} 145^{\circ} \mathrm{E}$ were not polluted by the occurrence of the post-spreading volcanism and had certainly guided the kinematic motions during the late stage of formation of the SCS. In order to find the conjugate segments of margins, the only way is to combine the trends of FZ and flow lines. Stage poles of rotation being located at a distance of 40 to $90^{\circ}(4,500$ to $10,000 \mathrm{~km})$ (Briais et al., 1993) in the SW direction of the SCS extinct ridge axis, the distortion of the fracture zones pattern east and west of the Zhongnan faults zone is not significant (Figure 11). Thus, the flow lines pattern has been established by assuming that spreading directions were $\mathrm{N} 145^{\circ}, \mathrm{N} 165^{\circ}$ and $\mathrm{N} 175^{\circ}$ in the pink, yellow, and blue areas defined in Figure 10 respectively and drawn to highlight conjugate segments of continental margins (Figure 11). The continental boundaries of these segments, at least in the southern part of the SCS, might have guided the early seafloor spreading motions. It is not in the scope of this paper to compare the segments of conjugate margins, but for clarity, we have named them. The East Dangerous Bank and Phu Khanh segments, the Spratley Islands and Penxi Bank segments, the Reed Bank and Macclesfield Bank segments, the Macclesfield Bank and Pearl River Mouth segments, the NW Palawan and Donghsa Island segments and the North Palawan and Tainan segments are the main identified conjugate margins segments. Though the Taiwan segment located east of the Tainan segment has no counterpart on the southern margin, the idea is to help to acquire or to identify conjugate profiles in order to compare and study conjugate margins and their processes of formation.

\subsection{Post-spreading volcanism}

Post-spreading volcanic features appear in Figures 9 and 10 (brown continuous lines). The largest seamounts appear as chains of seamounts in the central parts of both the east and southwest sub-basins. In the east sub-basin, south of Site U1431, the chain of seamounts is E$\mathrm{W}$ trending between $116^{\circ} \mathrm{E}$ and $118^{\circ} \mathrm{E}$ longitude, that is oblique to the $\mathrm{N} 055^{\circ}$ extinct spreading axis and then $\sim \mathrm{NE}-\mathrm{SW}$ further east, following approximately the $\mathrm{N} 055^{\circ}$ seafloor spreading 
trends. In the southwest sub-basin, two chains of post-spreading volcanic features are N-S trending along the $115^{\circ} \mathrm{E}$ and $115.5^{\circ} \mathrm{E}$ meridians. The three ovals with red dashed lines in Figure 8a belong to the pink domain and underline topographic features of intermediate size between the large post-rift volcanic features and the genuine seafloor spreading topographic features. These topographic features consist of a series of $\mathrm{N} 055^{\circ}$ closely spaced seafloor spreading features with their eastern borders trending N-S. We suggest that these N-S trends are traces of post-spreading fracture zones. In this hypothesis, the two chains of post-spreading volcanic features along the $115^{\circ} \mathrm{E}$ and $115.5^{\circ} \mathrm{E}$ meridians were emplaced along FZs of a N-S phase of extension associated with brittle deformation of the oceanic crust. Therefore, fracture zones of the post-rift extension phase are N-S trending and seafloor spreading features are E-W trending with post-rift volcanism emplaced along both directions. The amount of new oceanic crust created during the post-spreading phase, which lasts from $13 \mathrm{Ma}$ to $3.5 \mathrm{Ma}$ or less, is unknown but might range between a few $\mathrm{km}$ to a few tens of $\mathrm{km}$.

Figure $8 b$ displays the new one-minute free-air gravity map with details not available in previous versions. The post-spreading volcanic features are underlined by positive anomalies generally associated with negative anomalies on their southern sides. Ovals with red dashed lines highlight N-S negative trends already identified as N-S post-spreading fractures zones in Figure 8a. Thus, N-S trends identified on the free-air gravity map can be clearly attributed to the post-spreading N-S phase of extension in the area where seafloor spreading topographic features are $\mathrm{N} 055^{\circ}$ trending but not outside this area because directions of extension of the post-rift phase and of the general seafloor spreading fabric are almost the same. This does not mean that the post-rift extension has no expression outside the $\mathrm{N} 055^{\circ}$ pink area.

As shown in Figure 9, numerous large seamounts are identified as post-spreading volcanic features north of the central part of the east sub-basin, more rarely south of it. Figure 12 displays the new one-minute Bouguer gravity map that we have computed from the Sandwell et al. (2014) free-air gravity map and bathymetric data for the entire SCS. The white dashed lines highlight N-S negative trends mostly in a $\sim 150-\mathrm{km}$ wide corridor of the central part of both the east and southwest sub-basins, where seafloor spreading topographic features are $\mathrm{N} 055^{\circ}$ trending. Outside this area, the directions of extension of the post-rift phase and of the general seafloor spreading fabric being very close, only a few N-S trends generally located east of Macclesfield Bank were selected. They belong to the Zhongnan faults zone. However, as no bathymetric control exists for the vast majority of N-S trends identified on gravity data and as this short-wavelength N-S fabric is not only observed in the SCS but also in the Sulu 
Sea, Celebes Sea, some of these trends might be eventually considered as artifacts (Manuel Pubellier, personal, 2015).

Thus, considering than post-spreading FZs exist at least in the pink domain, the postspreading extensional pattern consists of 1) numerous magmatic bodies located in the east subbasin with the biggest ones lining E-W in the axial part of the east sub-basin, a few large magmatic bodies located in the southwest basin with the largest ones lining N-S along two fracture zones located immediately to the west of the Zhongnan faults zone, almost no significant magmatic bodies in the rest of the southwest basin, 2) the large zone of deformation approximately located along the Zhongnan faults zone might have absorbed the differential amount of extension between the east and southwest sub-basins.

We suggest that the post-spreading phase started along $\mathrm{N} 055^{\circ}$ directions and $\mathrm{N} 145^{\circ}$ conjugate directions considered as zones of weaknesses but finally breaks along E-W seafloor spreading and N-S FZ trends, which were not previously existing zones of weaknesses of the oceanic pink domain. Consequently, these features belong to an organized system of intra-plate deformation before the possible emergence of a steady-state system composed of E-W seafloor spreading segments and N-S transform faults and FZs. Other interpretations might be also possible. For example, a volcanic phase does not necessarily require a coincident phase of extension as magmas can find their way along previous zones of weaknesses (Dieter Franke, personal communication, 2015). However, in the SCS, post-spreading magmas find their ways not only along pre-existing zones of weaknesses but also along new trends, which are oblique to the already existing system of seafloor spreading trends and FZ.

The post-spreading volcanism has been dated $\sim 13-3.5 \mathrm{Ma}$ in the vicinity of the SCS ridge axis. The recent observation of hot venting on axial volcanic seamounts (Shu-Kun Hsu, personal communication ,2014) suggests that minor volcanic activity is still present today. In the central part of the east sub-basin, the post-spreading volcanism so largely overprints the $\mathrm{N} 055^{\circ}$ spreading fabric that published magnetic lineations were mostly E-W oriented instead of $\mathrm{N} 055^{\circ}$ oriented, demonstrating that the modeling of magnetic anomalies has to be updated.

\subsection{Location of the extinct spreading ridge}

The dense set of SCS magnetic data (Ishihara and Kisimoto, 1996) shows that postspreading volcanism partly hides the seafloor spreading magnetic fabric along the extinct spreading axis. Some magnetic lineations belonging to the seafloor spreading fabric are present within the pink domain, outside the E-W post-spreading volcanic chain and are parallel to the 
N055 ${ }^{\circ}$ bathymetric seafloor spreading trends identified on swath-bathymetric maps (Figures 8 and 10). A $N 055^{\circ}$ trending extinct ridge axis was tentatively proposed in Figure 10 but its exact location is not yet finalized as some $\mathrm{N} 145^{\circ}$ transform faults may offset the ridge axis.

Therefore, the suggested location of the extinct ridge axis and associated FZ pattern must be confirmed by a new re-identification and modeling of magnetic lineations. Thus, what was thought to be the extinct E-W ridge axis by Briais et al. (1993) and Barckhausen et al. (2014) is in fact the seafloor spreading axis of the post-spreading phase of extension.

\section{Kinematic evolution of the SCS}

Rifting initiated south of Mainland China from Late Cretaceous to Eocene and is observed in most of the offshore basins around the SCS (Cullen et al., 2010). Based on the regional distribution and timing of the rift-onset unconformity, Franke et al. (2014) showed that rifting migrated from east to west both on the northern and southern SCS margins. Extension was particularly important in the numerous basins of the Dangerous grounds area as attested by large lithospheric thinning factors compared to the extension of the Luconia block located immediately west of the Baram line, which bound the Dangerous Grounds area (Cullen, 2014). Cullen showed that the Baram line was not a major transform boundary during the early Cenozoic rifting phase and the following formation of the SCS, which accommodated the passage from a wide proto-SCS to a large subduction beneath NW Borneo.

Figure 13 is a plate tectonic sketch with the Eurasia (EU) plate supposed to be fixed. The Philippines Sea (PH) plate does not appear in this kinematic sketch. The eastward limit of the the east sub-basin follows the present day location of the Manila trench. The Palawan block, which belongs to the southern South China Sea (SSCS) plate, only appears in the plate reconstruction sketch of Figure $13 \mathrm{~b}$ as central and south Palawan were not above sea-level before late Middle Miocene ( 16-18 Ma) (Aurelio et al., 2014; Steuer et al., 2014). The starting point of our kinematic sketch of reconstructions (Figure 13a) is the model of Figure 10 in which former plate boundaries follow 1) the Xisha trough continuing through the Qiongdongnan basin until the Qui Nhon ridge located east of Vietnam (Rangin et al., 1995; Roques et al., 1997), 2) the topographic depression located south of Macclesfield Bank continuing through the Phu Khanh basin until the Qui Nhon ridge (Roques et al., 1997). However, the amount of N-S extension along this feature may be much smaller than along the Xisha trough and the Qiongdongnan basin. 3) the features which dissect the southern SCS margin (black dashed lines in Figure 13a). 
In general, the description of kinematic phases starts with the closure and ends with the present-day configuration. Here, the followed methodology was to successively close the pink, yellow and blue domains along the $\mathrm{N} 145^{\circ}, \mathrm{N} 165^{\circ}$ and $\mathrm{N} 175^{\circ}$ directions respectively. Several steps are proposed to progressively close the blue domain along the $\mathrm{N} 175^{\circ}$ direction. The approximate age of each step (chrons and corresponding ages) is given as a landmark, following Briais et al. (1993) and Barckhausen et al. (2014) modelings.

Figure 13b (early Miocene) corresponds to the closure of the pink domain along the $\mathrm{N} 145^{\circ}$ direction, knowing that the intermediate stage before closing the extreme western part of the southwest basin has been skipped. At the beginning of the formation of the pink domain the motion was probably transferred from the NE-SW trending Yongshu basin (Figure 13b) to the western extremity of the southwest basin. A significant decrease of the length of the transform fault between the east and southwest sub-basins is expected from the yellow phase $(\sim 140 \mathrm{~km})$ to the pink phase $(\sim 50 \mathrm{~km})$. In fact, as the Zhongnan faults zone is $30-50 \mathrm{~km}$ wide and corresponds to a transtensional fault system (Franke et al., 2014), the transform fault might be a series of two or more parallel transform faults whose total horizontal offset varies through time.

Figure 13c (late Oligocene) corresponds to the closure of the yellow domain along the $\mathrm{N} 165^{\circ}$ direction, knowing that the intermediate stage corresponding to the closure of the Spratley Islands and the Penxi Bank has been skipped. The Penxi Bank is about the same size that the Spratley islands feature (Figure 12). The length of the transform fault located between the east and southwest sub-basins inside the Zhongnan faults zone is $\sim 100 \mathrm{~km}$ prior to the opening of the yellow domain. The motion was probably transferred between Reed Bank and the Spratley islands (Figure 13c ), following a system of $\sim \mathrm{N} 165^{\circ}$ dextral strike-slip features giving rise to some tens of $\mathrm{km}$ of extension in the Reed Bank basin (Pubellier et al., 2015), then in the Palawan trough and beneath the Palute wedge. Then, the plate boundary joined, between the future Palawan and N Borneo, the extreme western part of the Sulu Sea, the location of the westernmost part of the dead proto-SCS located south of the future Palawan (Hall, 2002). Rifting processes occurred during the late Oligocene-early Miocene in both the Reed Bank basin, in the Palawan trough and beneath the Palute wedge located north of the future Palawan (Franke et al., 2014; Steuer et al., 2014). Once again, west of the SSCS plate, the EU/SSCS plate boundary followed previous zones of weaknesses active during the early Cenozoic rifting phase.

Figure 13d (late Oligocene) corresponds to the closure along the $\mathrm{N} 175^{\circ}$ direction of the remaining southwest sub-basin portion of blue domain located between Reed Bank and 
Macclesfield Bank. The respective positions of these two features is quite similar to the one in Barckhausen et al. (2014) reconstruction, where they are more E-W aligned. The western plate boundary between the SSCS and EU plates follows the NW-SE Ulugan fault located east of Reed Bank and then connects with the NE-SW oriented Palawan trough (Pubellier et al., 2015). A dextral shear motion occurred along the Ulugan fault with simultaneous extension in the NE Palawan basin, followed to the south by rifting processes occurring during the late Oligocene in the northeast Palawan trough and beneath the Palute wedge (Franke et al., 2014; Steuer et al., 2014). Further south, the Ulugan fault changes trend to $\sim \mathrm{N} 175^{\circ}$, cutting across the location of the future Palawan island and continuing to the Sulu Sea, the location of the dead proto-SCS (Hall, 2002).

Figure $13 \mathrm{e}$ (early Oligocene) corresponds to the closure along the $\mathrm{N} 175^{\circ}$ direction of the portion of the east sub-basin located east of Macclesfield Bank. When the width of the east subbasin became of the same order that the one of the NW east sub-basin, located north of Macclesfield bank, the ridge axis of the east sub-basin possibly jumped to south of the Macclesfield bank, extending further west to the Phu Khanh basin until the Qui Nhon ridge.

Figure $13 \mathrm{f}$ (early Oligocene) corresponds to the closure along the $\mathrm{N} 185^{\circ}$ direction of the remaining portion of the east sub-basin and of the Xisha trough. The detailed plate kinematic sketch between the two sketches of Figures 13e and 13f appears in Figure 14 and is basically controlled by the presence of a major fracture zone roughly oriented N-S and separating the NW east sub-basin from the east sub-basin. This FZ is not evidenced in the flat bathymetry of this region (Figure 9), but clearly appears in the gravity data (Sandwell et al., 2014) (Figure 12). It starts in the extreme northern part of the east and NW east sub-basins, brushes the NE extremity of Macclesfield Bank, then continues to the south and possibly joins the Zhongnan faults zone down to Reed Bank, exemplifying the role of the Zhongnan faults zone during the early SCS kinematic evolution, the structuration and formation of the east and southwest subbasins and even the N-S post-rifting volcanic phase of extension with the associated SCS intraplate deformation focused along the Zhongnan faults zone. The N-S to NNW-SSE direction of the trend in the NW east sub-basin suggests that the opening of the early SCS oceanic domain occurred along this $\sim \mathrm{N}-\mathrm{S}$ direction perhaps along a more NNW-SSE direction as suggested by Briais et al. (Briais et al., 1993). A tiny portion of oceanic domain located north of Reed Bank remains unexplained in the proposed fit of continents (Figure 13f). Negative Bouguer anomalies underlined the Xisha trough (Figure 12), which is a well-expressed topographic depression where rifting had not evolved in oceanic domain. Similarly, the Phu Khanh basin is 
also a well-expressed extensional feature where rifting had not evolved in an oceanic domain.

Figure 14a is a detail of the fit of continents of Figure 13f with in blue the remaining but not yet completely explained portion of oceanic crust. The beginning of $\mathrm{N} 175^{\circ}$ extension resulted in the formation of the early portion of oceanic crust in the east sub-basin (Figure 14b) which is bounded westward by the N-S to NNW-SSE fracture zone previously evidenced in Figure 12. The western boundary of the SSCS followed this FZ down to east of Reed Bank. Magnetic lineation C12 was formed at that time if we accept the onset of oceanic crust is 33 Ma (IODP Preliminary Report, 2014). Then the propagation of the seafloor spreading extended in the NW east sub-basin but not in the Xisha trough where rifting still occurred (Figure 14c), with a transform fault continuing to survive northeast of Macclesfield Bank between the east and NW east sub-basins. The Xisha trough is a failed rift arm that recorded thinning of the continental crust from $\sim 25 \mathrm{~km}$ to $8 \mathrm{~km}$ (Qiu et al., 2001), opened during early Oligocene and whose motion is transformed along the Qui Nhon ridge, located in the prolongation of the Red River fault system. Then, the Xisha trough failed rift arm aborted and extensional proceses possibly occurred south of the Macclesfield bank with a transform fault possibly running through the unexplained portion of oceanic crust located east of Macclesfield Bank (Figure 14d). South of the Macclesfield bank, rifting might have continued westward to the Phu Khanh (Nha Trang) basin located west of the Penxi bank, ending at the Qui Nhon ridge.

The proposed kinematic sketch for the SCS oceanic opening is globally satisfactory except for the stage between Figures $13 \mathrm{e}$ and $13 \mathrm{~d}$ where some inconsistencies might exist with the presence of a small portion of unexplained oceanic crust located east of Macclesfield Bank. Is this due to uncertainties in the proposed sketch of kinematic reconstructions, to errors in the proposed kinematic sketch or to errors in the identifications of continental plate boundaries in the south?

\section{Opening of the South China Sea within the SE Asia tectonic framework}

Numerous hypotheses have been proposed for the formation of the SCS in a general tectonic framework. Early models imply a formation of the SCS resulting of a N-S motion of the Palawan-Borneo block along the N-S eastern margin of Vietnam (Qui Nhon ridge) (Holloway, 1982; Taylor and Hayes, 1983; Ru and Pigott, 1986). Later, Briais et al. (1993) proposed that the opening of the SCS resulted from the extrusion of Indochina with respect to South China, in response to the penetration of India into Asia (Tapponnier et al., 1986), implying a 500-600 km left-lateral motion along the Red River fault system and no subduction 
of proto-oceanic crust south of the SCS. Based on kinematic considerations, it has been demonstrated thereafter that the amplitude of motion along the Red River fault system was $\sim 200 \mathrm{~km}$ ((Le Pichon et al., 1995; Rangin et al., 1995) and not 500-600 km. In addition, the subduction of a proto-SCS oceanic crust during the Eocene-early Miocene period is necessary to explain the NW verging Cretaceous-Miocene accretionary prism of north Borneo (Rangin et al., 1995; Morley, 2002). For Morley (2002) and Cullen (2014) the only strike-slip fault link between the Red River fault system and the north Borneo-south Palawan subduction zone occurred along the trend of the Red River fault system, which passes along strike into a rightlateral transform system along the Qui Nhon ridge and then to the Baram line, a feature which is connected to the north Borneo suture (Figure 15). Very recently, a simplified Cenozoic tectono-stratigraphic evolution of the SCS, based on the interpretation of a series of MCS profiles with the results of ODP and IODP drill holes, was proposed (Li et al., 2015). Though simplified, it matches the detailed kinematic sketch presented in figures 13 and 14.

In fact, we have shown that the SCS kinematic evolution is controlled by changes through time in the location of the EU/SSCS plate boundary (Figure 15). Two main episodes are identified:

1) From the fit of continents to chron C10 (Briais et al., 1993) (Figures 13e-f and 14): First, extension occurred in the east sub-basin, and simultaneously in the Xisha trough and in the NESW oriented Qiongdongnan (Hoang Sa) basin where the normal faults curve toward the south at the contact with the Qui Nhon ridge. This horsetail geometry of the fault system is interpreted as evidence for dextral motion along the $\mathrm{N} 160^{\circ}$ trending Qui Nhon ridge in this area (Roques et al., 1997). After that, the EU/SSCS plate boundary might extend southwestward from south of the Macclesfield bank to the Phu Khanh (Nha Trang) basin where similar horsetail geometry is observed at contact with the Qui Nhon ridge trending N-S in this area (Roques et al., 1997) (Figure 15). Thus, along the Qui Nhon ridge sensu stricto, the motion is right-lateral and only of a few tens of km. Roques et al. (1997) followed by Morley (2002), suggest that the subduction of the proto-SCS may be a possible drive for the opening of the SCS (Figure 15).

2) From chron C10 (Briais et al., 1993) to the end of SCS opening (Figures 13e to 13a), the geometry of the EU/SSCS plate boundary displays several common characters: to the east, the plate boundary is the eastward SCS termination arbitrarily taken here as the Manila trench. To the north the plate boundary is the ridge axis-transform fault system of the SCS. To the west, the boundary jumped from east to west (Figures 13a to 13d) explaining how the SCS 
progressively formed from east to west giving the characteristic V-shape of the SCS. To the south, the best candidate for the SSCS plate boundary is the north Borneo-south Palawan suture zone of the proto-SCS whose existence is needed not only in plate kinematic reconstructions (e.g. (Lee and Lawver, 1995; Hall, 2002)) but also from a geological point of view (e.g. (Rangin, 1991; Rangin and Silver, 1991; Morley, 2002). Thus, the amount of convergence absorbed by the subduction of the proto-SCS decreases from 500-600 km east of Palawan to a few tens of kilometers at the western extremity of the southwest basin. The successive segments of the EU/SSCS plate boundary located on the western side of the SSCS plate are partly NNW-SSE oriented i.e. oblique to the direction of SCS opening, suggesting the formation of simultaneous tensional basins. These extensional continental basins are located along each segment of plate boundary as the NE Palawan basin and Palawan trough, the Reed Bank basin, the Andu basin and the Yongshu basin (Figure 15).

In more detail and from east to west, the western EU/SSCS boundary follows the NNWSSE Ulugan fault (Figure 13d) located east of Reed Bank, and cutting across the northwest Palawan basin. As extension is $\mathrm{N} 175^{\circ}$, a few tens of $\mathrm{km}$ of extension might occurred in the northwest Palawan basin. Further south, the Ulugan fault changes trend to $\sim \mathrm{N} 175^{\circ}$, cutting across the future Palawan island and continuing to the location of the dead proto-SCS located north of the Sulu Sea (Hall, 2002) (Figure 15). Then, the western boundary of the SSCS jumped in between Reed Bank and the Spratley islands (Figure 13c), following a system of $\sim \mathrm{N} 175^{\circ}$ dextral strike-slip feature and NNW-SSE feature giving rise to some tens of $\mathrm{km}$ of extension in the Reed Bank basin, the Palawan trough and beneath the Palute wedge before joining, between the future Palawan and north Borneo islands, in the extreme western part of the Sulu Sea, the location of the westernmost part of the dead proto-SCS located south of the future Palawan (Hall, 2002) (Figure 15). Then, the western boundary of the SSCS jumped west of the Spratley islands (Figure 13b), probably following a system of $\sim \mathrm{N} 175^{\circ}$ dextral strike-slip feature and NNW-SSE feature giving rise to some tens of $\mathrm{km}$ of extension in the Yongshu and Andu basins located south of the Spratley islands before joining the north Borneo suture zone where part of the proto-SCS disappeared (Figure 15). This feature is difficult to properly follow as the counterclockwise rotation of Borneo/EU commenced before and continued after seafloor spreading started in the SCS (Fuller et al., 1999). Finally, the western boundary of the SSCS jumped west of the oceanic part of the southwest basin (Figure 13a) and probably joins the north Borneo suture zone along the Baram line.

The onset of end-rift or breakup unconformities (ERU or BU) varies in these basins from 
$\sim 32 \mathrm{Ma}$, (early Oligocene), 30 Ma (early Oligocene), 27 Ma (late Oligocene), 22 Ma (early Miocene) to $17 \mathrm{Ma}$ (Middle Miocene) from east to west (Franke et al., 2014) (Figure 16).

Segment 1 on the southern margin moved southward along the fault located west of this segment (Ulugan Fault) from $32 \mathrm{Ma}$ (BU onset in the NW Palawan basin, Figure 16) to $30 \mathrm{Ma}$ (BU onset on the Reed Bank, Figure 16). Note that the onset of oceanic crust for the conjugate segment (Tainan segment) is 33 Ma (IODP Preliminary Report, 2014), a value similar to the BU onset in the NW Palawan basin. Segment 2 moved southward (together with segment 1) along the fault located west of this segment from $30 \mathrm{Ma}$ (BU onset on the Reed Bank, Figure 16) to $27 \mathrm{Ma}$ (BU onset in the SW Palawan trough, Figure 16). Segment 3 moved southward (together with segments 1 and 2) along the fault located west of this segment from $27 \mathrm{Ma}$ (BU onset in the SW Palawan trough, Figure 16) to $22 \mathrm{Ma}$ (BU onset in the Dangerous grounds, Figure 16). Segment 4 moved southward (together with segments 1, 2 and 3) along the fault located west of this segment from $22 \mathrm{Ma}$ (BU onset in the Dangerous grounds, Figure 16) to 17 Ma (ERU onset in the NW Borneo, Figure 16). These ages nicely correspond to the period during which the western EU/SSCS plate boundary jumped from east to west in Figures 13 and 14, giving a geological significance to these segments of the EU/SSCS plate boundary.

Though this sketch of the formation of the SCS in a general tectonic framework is preliminary, we can suggest a few important kinematic constraints: 1) During the first phases of opening of the SCS, from the fit of continents to chron C10 (32 Ma), the N175 ${ }^{\circ}$ extension observed in the Xisha trough and possibly south of the Macclesfield depression extends to the Qui Nhon ridge where normal faults curve toward the south with horsetail geometries interpreted as evidence for a few tens of $\mathrm{km}$ of total dextral motion along the Qui Nhon ridge. 2) Since chron C10 and until the end of the SCS opening, the western SSCS/EU plate boundary jumped westward several times from the Ulugan fault to the western limit of the oceanic southwest basin, explaining the progressive formation of the SCS from east to west and giving the characteristic V-shape of the SCS. All the western portions of the SSCS/EU plate boundaries were connected to the subducting proto-SCS located north of the Sulu Sea and south of the future Palawan and inside north Borneo further west. This hypothesis does not require a 500-600 km left-lateral motion along the Red River fault system resulting in the opening of the SCS (e.g. (Briais et al., 1993)) but only a few tens of kilometers of right-lateral motion along the Qui Nhon ridge which is part of the Red River fault system during the early stage of opening of the East Basin (early Oligocene), followed by a few tens of kilometers of right-lateral motion along the Baram line which is part of the Red River fault system during the 
late stage of opening of the SCS (22-17 Ma). A few kilometers to a few tens of kilometers of right lateral motion might still have occurred during the post-spreading phase of extension along the Baram line. Therefore, the subduction of the proto-SCS occurred during the whole SCS formation and the SCS opening was fully compensated by an equivalent amount of protoSCS subduction. During the SCS opening, only a few tens of kilometers of motion occurred along the Red River fault-Qui Nhon ridge-Baram line system connected to the eastern part of the suture zone associated with the subduction of the proto-SCS. This motion is probably associated with a similar amount of proto-SCS subduction and the maximum amount of protoSCS subduction (400-500 km) occurred east of the SCS, near the eastern part of the suture, not along the Red River Fault system as previously proposed (Briais et al., 1993). The amount of proto-SCS subduction decreases from east to west along the different segments of margins, suggesting that the shape of the proto-SCS mimics the one of the present-day SCS. Published $\mathrm{P}$ - and S-wave tomographic data suggest that the proto-SCS was located beneath the presentday SCS (Sabin Zahirovic and Jonny Wu, personal communications, 2015) in opposition with geologists who proposed a subduction in the other sense (e.g. (Cullen et al., 2010; Franke et al., 2014)).

\section{Conclusions}

The main conclusions of this study are as follows:

1) The nature of the crust of the northeastern part of the SCS located north of chron C12 (32 Ma) is not oceanic but thinned continental crust intruded by volcanic elongated features emplaced 17-22 Ma ago. There, the end of the rifting episode at IODP Site 1435 located close to the ocean-continent boundary is $\sim 33 \mathrm{Ma}$.

2) Based on the identifications of magnetic anomalies, the end of the SCS spreading could be either 15.5 or 20.5 Ma (Briais et al., 1993; Barckhausen et al., 2014) or something else. As the post-spreading magmatic activity ( 8-3.5 Ma) largely masks the spreading fabric in particular near the axis of the east sub-basin, the location of the axial magnetic anomaly (extinct spreading axis) and spreading rates are not reliable.

3) The contoured map of the dense set of magnetic data shows that post-spreading volcanics hide the seafloor spreading magnetic fabric along the extinct spreading axis. However, a few magnetic lineations belonging to the magnetic seafloor spreading fabric are still present and parallel to the $\mathrm{N} 055^{\circ}$ bathymetric seafloor spreading trends identified on swath-bathymetric maps, suggesting the extinct ridge axis is N055 
trending with potential $\mathrm{N} 145^{\circ}$ transform faults.

4) Oceanic domains with different seafloor spreading directions have been delimited and correspond to $\mathrm{N} 055^{\circ}, \mathrm{N}^{\circ} 75^{\circ}$ and $\mathrm{N} 085^{\circ}$ seafloor spreading lineaments. The width of the $\mathrm{N} 055^{\circ}$ domain is about the same in the east and southwest sub-basins, suggesting that the two sub-basins opened simultaneously from early to middle Miocene and roughly ceased to open at the same time in the two sub-basins. On each side of the Zhongnan faults zone, when the $\mathrm{N} 055^{\circ}$ domain is closed, the width of the $\mathrm{N} 075^{\circ}$ domain is about the same in the two sub-basins. The Zhongnan faults zone acted as a fracture zone system during the opening of the pink and yellow domains, with horizontal offsets varying from $\sim 50 \mathrm{~km}$ to $\sim 140 \mathrm{~km}$. However, the $\mathrm{N} 085^{\circ}$ domain is mainly identified in the east sub-basin and very little in the southwest sub-basin.

5) The flow-line pattern defined from the seafloor spreading lineaments and the few identified FZs have been used to highlight conjugate segments of continental margins: East Dangerous Bank and Phu Khanh segments, the Spratley islands and Penxi Bank segments, Reed Bank and Macclesfield Bank segments, Macclesfield Bank and Pearl River Mouth segments, the NW Palawan and Donghsa Island segments and the North Palawan and Tainan segments.

6) During the first phases of opening of the SCS, from the fit of continents to chron C10 (32 Ma), the $\mathrm{N} 175^{\circ}$ extension observed in the Xisha trough and possibly south of the Macclesfield bank extends to the Qui Nhon ridge where normal faults curve toward the south with horsetail geometries interpreted as evidence for a few tens of $\mathrm{km}$ of dextral motion along the Qui Nhon ridge. Since chron 10 and until the end of SCS opening, the western EU/SSCS plate boundary jumped westward several times from the Ulugan fault to the western limit of the southwest basin, explaining the progressive formation of the SCS from east to west, giving the characteristic V-shape of the SCS. In other words, the final V-shape of the SCS is the result of the kinematic evolution of the SCS. During the first phase of opening of the SCS, a narrow band of oceanic domain was created in the east and NW east sub-basins. West of the NW east sub-basin, the extension corresponds to continental rifting up to the Qui Nhon ridge. Then the opening of the SCS follows a different mechanism. The oceanic domain first formed in a N-S stripe, then later on in a second N-S stripe adjacent to the first stripe on its western side ... until the last stripe, which started to form just before the end of spreading. As spreading stops at the same time in all the stripes, the result is the formation of a V-shape SCS. The whole opening 
of the SCS occurred simultaneously with the subduction of the proto-SCS. The amount of proto-SCS subduction decreasing from east to west along the different segments of margins, the shape of the proto-SCS mimics the one of the present-day SCS.

Acknowledgments: This paper benefits from early discussions concerning the geodynamics of the South China Sea (SCS) with Jiabiao Li and Weiwei Ding during the 2012 two weeks stay of one of us (JCS) in the $2^{\text {nd }}$ Institute of Oceanography, Hangzhou. We also thank Shu-Kun Hsu, Zhen Sun, Minghui Zhao, Udo Barckhausen, Dieter Franke, Claude Rangin, Manuel Pubellier, Jonny Wu and John Suppe for discussions concerning the kinematics of the South China Sea, the formation of the northern South China Sea continental margins and processes of Taiwan mountain building. We particularly thank Dieter Franke and Manuel Pubellier for their careful reviews of the manuscript.

\section{References}

Barckhausen, U., Engels, M., Franke, D., Ladage, S. \& Pubellier, M. 2014. Evolution of the South China Sea: Revised ages for breakup and seafloor spreading. Marine and Petroleum Geology, 58, 599-611, doi:10.1016/j.marpetgeo.2014.02.022.

Barckhausen, U. \& Roeser, H. A. 2004. Seafloor spreading anomalies in the South China Sea revisited. In: Clift, P., Wang, P., Kuhnt, W. \& Hayes, D. E. (eds) Continent-Ocean Interactions Within East Asian Marginal Seas, 149, American Geophysical Union monograph, Washington, D.C., pp. 121-125, doi:10.1029/149GM07.

Briais, A., Patriat, P. \& Tapponnier, P. 1993. Updated interpretation of magnetic anomalies and seafloor spreading stages in South China Sea: Implications for the Tertiary tectonics of Southeast Asia. Journal of Geophysical Research, 98, 6299-6328.

Bullock, A. D. \& Minshull, T. A. 2005. From continental extension to seafloor spreading: Crustal structure of the Goban Spur rifted margin, southwest of the UK. Geophysical Journal International, 163, 527-546, doi:10.1111/j.1365-246X.2005.02726.x.

Christensen, N. I. \& Mooney, W. D. 1995. Seismic velocity structure and composition of the continental crust: A global view. Journal of Geophysical Research, 100, 9761-9788.

Chung, S.-L., Sun, S.-S., Tu, K., Chen, C.-H. \& Lee, C.-Y. 1994. Late Cenozoic basaltic volcanism around the Taiwan Strait, SE China Sea: Product of lithosphere-asthenosphere interaction during continental extension. Chem. Geol., 112, doi:10.1016/00092541(94)90101-5.

Ding, W.-W., J.-B. Li, P. D. Clift \& ODP Expedition 349 Scientists. 2016. Spreading dynamics and sedimentary process of the Southwest Sub-basin, South China Sea: Constraints from multi-channel seismic data and IODP Expedition 349. Journal of Asian Earth Sciences, 115, 97-113, doi.org/10.1016/j.jseaes.2015.09.013.

Franke, D., Savva, D., Pubellier, M., Steuer, S., Mouly, B., Auxietre, J.-L., Meresse, F. \& Chamot-Rooke, N. 2014. The final rifting evolution in the South China Sea. Marine and Petroleum Geology, 58, 704-720, doi: org/10.1016/j.marpetgeo.2013.11.020.

Fuller, M., Ali, J. R., Moss, S. J., Frost, G. M., Richter, B. \& Mahfi, A. 1999. Paleomagnetism of Borneo. J. Asian Earth Sci., 17, 3-24.

Gradstein, F. M., Ogg, J. G. \& Smith, A. G. 2004. A geologic time scale 2004. Cambridge 
University Press, Cambridge, UK, 589 pages.

Hall, R. 2002. Cenozoic geological and plate tectonic evolution of SE Asia and the SW Pacific: computer-based reconstructions, models and animations. Journal of Asian Earth Sciences, 20, 353-431.

Haq, B. U., Hardenbol, J. A. N. \& Vail, P. R. 1987. Chronology of fluctuating sea levels since the Triassic. Science, 235, 1156-1167.

Holloway, N. H. 1982. North Palawan block, Philippines - its relation to Asian mainland and role in evolution of South China Sea. American Association of Petroleum Geologists Bulletin, 66, 1355-1383.

Honza, E. 1995. Spreading mode of backarc basins in the western Pacific. Tectonophysics, 251, 139-152, doi:10.1016/0040-1951(95)00054-2.

Hsu, S.-K., Yeh, Y.-C., Doo, W.-B. \& Tsai, C.-H. 2004. New bathymetry and magnetic lineations in the northernmost South China Sea and their tectonic implications. Marine Geophysical Researches, 25, 29-44, doi:10.1007/s11001-005-0731-7.

IODP Preliminary Report 2014. South China Sea tectonics: Opening of the South China Sea and its implications for southeast Asian tectonics, climates, and deep mantle processes since the late Mesozoic. International Ocean Discovery Program Preliminary Report, 349, http://dx.doi.org/10.14379/iodp.pr.349.2014.

Ishihara, T. \& Kisimoto, K. 1996. Magnetic anomaly map of East Asia 1:4.000.000, [CD- ROM]. Geological Survey of Japan and Coordinating Committee for Costal and Offshore Geoscience Programs in East and Southeast Asia (CCOP).

Koppers, A. P. 2014. On the Ar/Ar dating of low-potassium ocean crust basalt from IODP Expedition 349, South China Sea. 2014 AGU Fall Meeting, T31E-03.

Le Pichon, X., Huchon, P., Rangin, C. \& Coulon, O. 1995. Formation of Indochinese continental margin and of the South China Sea basin: Facts and questions. In Cenozoic evolution of the Indochina Peninsula Hanoi (Vietnam).

Lee, T.-Y. \& Lawver, L. A. 1995. Cenozoic plate reconstruction of Southeast Asia. Tectonophysics, 251, 85-138.

Lester, R., Van Avendonk, H. J. A., McIntosh, K., Lavier, L., Liu, C.-S., Wang, T.-K. \& Wu, F. 2014. Rifting and magmatism in the northeastern South China Sea from wide-angle tomography and seismic reflection imaging. J. Geophys. Res., 119, 2305-2323, doi:10.1002/2013JB010639.

Li, C.-F. \& al. 2015. Ages and magnetic structures of the South China Sea constrained by deep tow magnetic surveys and IODP Expedition 349. Geochemistry, Geophysics, Geosystems, doi: 10.1002/2014GC005567.

Li, C.-F., Li, J.-B., Ding, W.-W., Franke, D. \& et al. 2015. Seismic stratigraphy of the central South China Sea basin and implications for neotectonics. Journal of Geophysical Research, doi: 10.1002/2014JB011686.

Li, J.-B. 2011. Dynamics of the continental margins of South China Sea: Scientific experiments and research progresses. Chinese Journal of Geophysics, 54, 2993-3003.

Li, J.-B., Ding, W.-W., Gao, J.-Y., Wu, Z.-Y. \& Zhang, J. 2011. Cenozoic evolution model of the sea-floor spreading in South China Sea: New constraints from high resolution geophysical data. Chinese Journal of Geophysics, 54, 3004-3015, doi:10.3969/j.issn.0001-5733.2011.12.003.

Li, J.-B., Ding, W.-W. \& Wu, Z.-Y. 2012. The propagation of seafloor spreading in the southwestern subbasin, South China Sea. Chinese Science Bulletin, 57, doi: $10.1007 / \mathrm{s} 11434-012-5329-2$.

Morley, C. K. 2002. A tectonic model for the Tertiary evolution of strike-slip faults and rift basins in SE Asia. Tectonophysics, 347, 189-215.

Pubellier, M., Savva, D., Aurelio, M. A., Sapin, F. \& Chamot-Rooke, N. 2015. Structural map 
of the South China Sea. Commission for the Geological Map of the World, Paris.

Qiu, X., Ye, S., Wu, S., Shi, X., Zhou, D., Xia, K. \& Flueh, E. R. 2001. Crustal structure across the Xisha Trough, northwestern South China Sea. Tectonophysics, 341, 179-193, doi: org/10.1016/S0040-1951(01)00222-0.

Rangin, C. 1991. The Philippine mobile belt: a complex plate boundary. Journal of Southeast Asian Earth Sciences, 6, 209-220.

Rangin, C., Klein, M., Roques, D., Le Pichon, X. \& Trong, L. V. 1995. The Red River fault system in the Tonkin Gulf, Vietnam. Tectonophysics, 243, 209-222, doi: 10.1016/00401951(94)00207-P.

Rangin, C. \& Silver, E. A. 1991. Neogene tectonic evolution of the Celebes-Sulu basins: New insights from Leg 124 drilling. Proceedings ODP, Scientific Results, 124, 51-63.

Roques, D., Matthews, S. J. \& Rangin, C. 1997. Constraints on strike-slip motion from seismic and gravity data along the Vietnam margin offshore Da Nang: Implications for hydrocarbon prospectivity and opening of the East Vietnam Sea. In: Hall, R. \& Blundell, D. (eds) Tectonic Evolution of SE Asia, 106, Geol. Soc. London, pp. 341-353.

Ru, K. \& Pigott, J. D. 1986a. Episodic rifting and subsidence in the South China Sea. American Association of Petroleum Geologists Bulletin, 70, 1136-1155.

Ru, K. \& Pigott, J. D. 1986b. Episodic rifting and subsidence in the South China Sea. Amer. Assoc. Petr. Geol. Bull., 70, 1136-1155.

Sandwell, D. T., Müller, R. D., Smith, W. H. F., Garcia, E. \& Francis, R. 2014. New global marine gravity model from CryoSat-2 and Jason-1 reveals buried tectonic structure. Science, 346, 65-67, doi: 10.1126/science.1258213.

Sibuet, J.-C. \& Hsu, S.-K. 2004. How was Taiwan created? Tectonophysics, 379, 159-181.

Sibuet, J.-C., Hsu, S.-K. \& Debayle, E. 2004. Geodynamic context of the Taiwan orogen. In: Clift, P., Wang, P., Kuhnt, W. \& Hayes, D. E. (eds) Continent-Ocean Interactions Within East Asian Marginal Seas, 149, American Geophysical Union monograph, Washington, D.C., pp. 127-158.

Sibuet, J.-C. \& Tucholke, B. 2012. The geodynamic province of transitional crust adjacent to magma-poor continental margins. In: Nemcock, N., Sinha, S., Mohriak, W., Danfort, A., Post, P., Brown, D. \& Tari, G. (eds) Divergent Conjugate margins, 369, Geological Society of London, pp. 429-452, doi: 10.1144/SP369.15.

Steuer, S., Franke, D., Meresse, F., Savva, D., Pubellier, M. \& Auxietre, J.-L. 2014. OligoceneMiocene carbonates and their role for constraining the rifting and collision history of the Dangerous Grounds, South China Sea. Marine and Petroleum Geology, 58, 644-657, doi: org/10.1016/j.marpetgeo.2013.12.010.

Tapponnier, P., Peltzer, G. \& Armijo, R. 1986. On the mechanics of collision between India and Asia. In: Coward, M. \& Ries, A. C. (eds) Collision tectonics, 19, Geol. Soc. London, pp. 115-157, doi: 10.1144/GSL.SP.1986.019.01.07.

Taylor, B. \& Hayes, D. E. 1983. Origin and history of the South China Sea basin. In: Hayes, D. E. (ed.) The tectonic and geologic evolution of Southeast Asian Seas and Islands, Part 2, Geophys. Monogr. Ser., 27, AGU, Washington D.C., pp. 23-56.

Tejada, M. L., Koppers, A. P., Zhang, G. \& Huang, X.-L. 2014. Petrology and geochemistry of igneous basement rocks, IODP Expedition 349, South China Sea. 2014 AGU Fall Meeting, T33C-4694.

Wang, T. K., Chen, M.-K., Lee, C.-S. \& Xia, K. 2006. Seismic imaging of the transitional crust across the northeastern margin of the South China Sea. Tectonophysics, 412, 237-254, doi:10.1016/j.tecto.2005.10.039.

White, R. S., McKenzie, D. \& O'Nions, K. 1992. Oceanic crustal thickness from seismic measurements and rare earth element inversions. Journal of Geophysical Research, 97, 19,683-619,715. 
Yao, B., Zeng, W., Hayes, D. E. \& Spangler, S. 1994. The geological memoir of South China Sea surveyed jointly by China and USA. Wuhan (China Univ. Geosci. Press), in Chinese.

Yeh, Y.-C., Hsu, S.-K., Doo, W.-B., Sibuet, J.-C., Liu, C.-S. \& Lee, C.-S. 2012. Crustal features of the northeastern South China Sea: Insights from seismic and magnetic interpretations. Mar. Geophys. Res., doi:10.1007/s11001-012-9154-4.

Yeh, Y.-C., Sibuet, J.-C., Hsu, S.-K. \& Liu, C.-S. 2010. Tectonic evolution of the northeastern South China Sea from seismic interpretation. J. Geophys. Res., 115, B06103, doi:10.1029/2009JB006354.

Yubo, M., Shiguo, W., Fuliang, L., Dongdong, D., Qiliang, S., Yintao, L. \& Mingfeng, G. 2011. Seismic characteristics and development of the Xisha carbonate platforms, northern margin of the South China Sea. J. Asian Earth Sci., 40, 770-783.

Zhou, D., Ru, K. \& Chen, H. 1995. Kinematics of Cenozoic extension on the South China Sea continental margin and its implications for the tectonic evolution of the region.

Tectonophysics, 251, 161-177, doi:10.1016/0040-1951(95)00018-6. 


\section{Legend of Figures}

Figure 1: Magnetic lineations in the South China Sea (SCS). a) From Briais et al. (1993) with inset presenting the evolution of seafloor spreading geometry in the east sub-basin. b) SCS bathymetric map with magnetic profiles shown as wiggles along ship tracks and magnetic anomaly interpretation (thin yellow lines) from Barckhausen et al. (2014). Thick yellow lines are abandoned spreading ridges and numbers indicate magnetic chrons. ODP Site 1148 (white dot) and Leg 349 IODP Sites (red dots) are indicated.

Figure 2: Free-air gravity map of the northeastern SCS showing chrons 15 to 17 (thick yellow lines) (Hsu et al., 2004) inside the domain bounded by AA', BB' and the Luzon-Ryukyu transform plate boundary (LRTPB) defined by the hachured area. White thin lines, bathymetric contours every km. Black crosses and dashed black lines, structural highs (elongated volcanic intrusions) and elongated depressions established from seismic data. Thick black dashed line, change in seafloor spreading direction. Thin black lines with double arrows, ridge axes determined from swath-bathymetric data (Yeh et al., 2010). To the south, chrons C12 and younger (Briais et al., 1993). MCS lines and refraction lines OBS2001 and MGL905-20 (black lines) with locations of OBSs (red dots). White star, dredging location where basalts were dated $22 \mathrm{Ma}$ (Hsu et al., 2004).

Figure 3: a) Velocity-depth profiles along lines OBS2001 (Wang et al., 2006) (OBSs 1 to 11), MGL905-20 (thick black line) (Lester et al., 2014) and MCS stack velocities (in blue) from portions of lines MGL0905-3, 4, 5, 10, 20, 25A located inside the domain bounded by AA', BB' and the LRTPB (lines MGL0905-10 and 20 are located in Figure 1, other lines in Yeh et al. (2010)). The area in grey indicates the velocity bounds for normal oceanic crust aged 59-144 Ma (White et al., 1992); the area in light green shows the bounds of velocity-depth profiles through the zone of exhumed mantle west of Iberia (Bullock and Minshull, 2005); the orange thick line is the average velocity curve for extended continental crust with horizontal bars representing \pm 1 standard deviation (Christensen and Mooney, 1995). P-wave velocity models along profiles MGL905-20 (Lester et al., 2014) (b) and OBS2001 (Wang et al., 2006) (OBSs 1 to 11) (c). A, B, C and D are buried or outcropping volcanic ridges. 
Figure 4: Structural framework of the northeastern South China Sea (SCS), magnetic lineations and half-spreading rates modified from Briais et al. (1993). a) Bathymetry every $200 \mathrm{~m}$ in grey and every $1000 \mathrm{~m}$ in dark grey. Dark blue lines, magnetic lineations adapted from Briais et al. (Briais et al., 1993); thick green lines, FZs; dotted thick green lines, ridge jumps; red crosses and dashed red lines, elongated structural highs and depressions established from seismic data. Green, light blue and dark blue are oceanic domains formed during kinematic phases marked by changes in spreading rates, spreading directions or both (Briais et al., 1993). Yellow, thinned continental crust; light pink, proto-SCS, which is oceanic or thinned continental crust. DF, deformation front. b) Half- spreading rates in the northeastern SCS calculated from chron C12 to 15.5 Ma by using Briais et al. (1993) synthetic magnetic models with the Gradstein et al. (2004) time-scale. T1 is an extensional tectonic phase and T2 is associated with the emplacement of volcanic ridges located between AA', BB' and the LRTPB. c) Spreading directions are calculated by assuming that they are perpendicular to the trends of magnetic lineations.

Figure 5: Revised interpretation of MCS profile MGL0905-20 (Yeh et al., 2012) located in Figure 1. Based on refraction results (Figure 2) and the interpretation of MCS data, the nature of the crust is thinned continental crust (in yellow) and oceanic (in light green) in the extreme southern part of the profile with some underplating at the base of the crust. Tectonic phases T1 and $\mathrm{T} 2$ are underlined by seismic unconformities (green and blue lines, respectively). The freeair gravity anomaly and inverted magnetization appear in the upper part of the figure (Yeh et al., 2012). Sills are present between unconformities T1 and T2. FC, Formosa Canyon.

Figure 6: Revised interpretation of MCS profile MCS689-1 (Yeh et al., 2012). The profile is perpendicular to magnetic lineations trends identified as chrons C15-C17 (Hsu et al., 2004) and shown here as magnetization anomalies (Yeh et al., 2012). These magnetic lineations are associated with volcanic features intruded through the thinned continental crust as shown by refraction results. Overlying sediments were uplifted up to the T2 unconformity (early Miocene) showing that magnetic lineations $\mathrm{C} 15$ to $\mathrm{C} 17$ are not seafloor spreading lineations.

Figure 7: Post-stack time migration of MCS profile MGL0905-10 (Yeh et al., 2012) and revised interpretation. The profile cut across magnetic lineations identified as chrons $\mathrm{C} 15$ and C16 (Hsu et al., 2004). These magnetic lineations (Figure 1) are associated with volcanic 
features, which have uplifted already deposited sediments up to the T2 unconformity. North of the LRTPB, below the proto-SCS, the underplating is still present but disappears northeast of CMP20000. From refraction results, the nature of the crust is thinned continental crust. Sills are present between unconformities T1 and T2. FC, Formosa canyon; PC, Penghu canyon; DF deformation front.

Figure 8: Detailed swath-bathymetric map (Barckhausen et al., 2014), free-air gravity map (Sandwell et al., 2014) with superimposed bathymetry and contoured magnetic anomalies (Ishihara and Kisimoto, 1996) located in Figure 1, in the central part of the South China Sea (SCS), on each side of the Zhongnan faults zone (ZFZ). Red dot, Leg 349 IODP Site U1431. a) White arrows points toward the seafloor spreading lineaments and are trending differently in the axial part of Figure 8a than outside of it. Red ovals underline uplifted seafloor spreading features during the N-S post-spreading extension. Note that seafloor-spreading features are not perpendicular to the N-S post-spreading fabric features. White ovals (1,2 and 3$)$ underline nonuplifted seafloor spreading features of the spreading fabric, which are associated to perpendicular FZs belonging to the spreading fabric. b) Red ovals underline N-S post-spreading features which are clearly oblique to the $\mathrm{N} 055^{\circ}$ seafloor spreading fabric and the $\mathrm{N} 145^{\circ} \mathrm{FZ}$ features of the spreading fabric shown in Figure 8a. The white oval underlines a non-uplifted seafloor spreading features of the spreading fabric and the associated perpendicular FZs belonging to the spreading fabric but it is extremely difficult to separate a N-S post-spreading features from a FZ of the spreading fabric, which also trends roughly N-S outside the central area. c) Black arrows point toward the direction of magnetic lineations of the spreading fabric and are trending roughly E-W outside of the central part of Figure 8c. These seafloor spreading directions are exactly the same as in Figure 8a but we must notice that in the axial part of the SCS, many E-W trending lineations (red arrows) of the post-spreading fabric obliterate the N055 spreading fabric.

Figure 9: Bathymetric map of the South China Sea (SCS) (Barckhausen et al., 2014), with observed seafloor spreading lineaments (thin white segments) and FZs of the spreading fabric (thin yellow segments) extracted from available published swath-bathymetric maps, wellexpressed negative magnetic lineations (light blue segments) extracted from the magnetic anomaly contoured map (Ishihara and Kisimoto, 1996) and post-rift volcanism (brown continuous lines) extracted from available published swath-bathymetric maps. The continent- 
ocean boundary (thick white line) was established following Cameselle et al. (2015) for the SCS northwestern margin, Li et al. (2015) and Ding and Li (2011) for the rest of the SCS. The Manila trench (thick white line with triangles) bounds the oceanic portion of the SCS. Black lines bound domains with different seafloor spreading trends.

Figure 10: Summary of observed seafloor spreading trends in the South China Sea (SCS) extracted from Figure 9. Black lines bound domains with different seafloor spreading trends: the pink domain with $\mathrm{N} 055^{\circ}$ trends, the yellow domain with $\mathrm{N} 075^{\circ}$ trends, the blue domain with $\mathrm{N} 085^{\circ}$ trends. Large red arrows show the direction of extension during the formation of the pink domain. The outline of the proposed extinct spreading axis is a combination of $\mathrm{N} 055^{\circ}$ seafloor spreading trends and $\mathrm{N} 145^{\circ} \mathrm{FZs}$ but is still preliminary. The black dashed lines are features, which acted as plate boundaries during the formation of the SCS. ZFZ, Zhongnan faults zone; EU, PH and SSCS are Eurasia, Philippine Sea and Southern South China Sea plates respectively.

Figure 11: Bathymetric map of the South China Sea (SCS) (Barckhausen et al., 2014) with observed FZs of the spreading fabric (thin yellow segments). The continent-ocean boundary (thick white line) and the Manila trench (thick white line with triangles) bound the oceanic portion of the SCS. Black lines bound domains with different seafloor spreading trends as shown in Figure 10. The kinematic flow lines (thin white lines) show conjugate segments of passive margins located north and south of the SCS, with their names on each side of the SCS.

Figure 12: Bouguer anomaly map computed from the free-air gravity map (Sandwell et al., 2014) with superimposed bathymetric contours. The 3D Bouguer anomaly map was computed with assigned densities of 1.03 and $2.3 \mathrm{~g} / \mathrm{cm}^{3}$ for water and sediments respectively. The color scale ranges from -200 to $+200 \mathrm{mGal}$. The thick white line is the continent-ocean boundary (COB) and the thick white line with triangles the Manila trench. Brown contours underline the post-spreading volcanism as already suggested (Barckhausen et al., 2014). Negative Bouguer gravity anomalies (yellow large dahed line) underline the E-W line of post-spreading seamounts in the east sub-basin, which does not follow the $\mathrm{N} 055^{\circ}$ seafloor spreading directions of the central part of the east sub-basin (Figure 10). In general, seafloor spreading lineaments and fracture zones (FZ, dotted yellow lines) are underlined in the Bouguer map inside the $\mathrm{N} 055^{\circ}, \mathrm{N}^{\circ} 75^{\circ}$ and $\mathrm{N} 085^{\circ}$ trending seafloor spreading lineaments observed in areas between 
continuous black lines, between dashed black lines and outside of dashed black lines, respectively. Numerous FZs underlined by yellow dotted lines and belonging to the oldest oceanic domain are parallel to the kinematic flow lines (thin white lines). The N-S white dotted lines underline the post-spreading N-S trends evidenced in the Bouguer gravity anomaly map only within the $\mathrm{N} 055^{\circ}$ domain as already shown by bathymetric trends (Figure 8a, red ovals) and within the Zhongnan faults zone.

Figure 13: Plate kinematic reconstruction sketches of the South China Sea (SCS) at different epochs. Indications of time are given by comparison with ages of magnetic lineations of Briais et al. (1993) and Barckhausen et al. (2014) and by using their time scales. The large arrows give the directions of extension from the older stage to the considered stage. The plate boundary (in red) between the Eurasia (EU) and the southern SCS (SSCS) plates is given for all reconstructions before re-adjustment for the younger step. The eastern limit of the east subbasin corresponds to the Manila trench. The black dashed lines are features, which acted as EU/SSCS plate boundaries at some stage during the SCS formation. They are important features to explain the step-by-step SCS opening in a broader context. ZFZ, Zhongnan faults zone. Central and south Palawan in dashed lines and light green before their formation by underthrusting of late Oligocene-early Miocene Nido limestones before the end of early Miocene (Aurelio et al., 2014; Steuer et al., 2014).

Figure 14: Tentative plate kinematic sketches of the early South China Sea (SCS) opening with two proposed new steps in between Figures 13e and 13f. The small blue arrows give the directions of extension $\left(\mathrm{N} 175^{\circ}\right)$ since the closure. The plate boundary configuration (in red) between Eurasia (EU) and the southern SCS (SSCS) plates is given in figures 14b to $14 \mathrm{~d}$, before any re-adjustment for the following younger step. For example, the seafloor spreading axis in Figure 14d was active from the step of Figure 14c to the step of Figure 14d. In contrast, the seafloor-spreading axis in Figure 13e was active from the step of Figure 13e to the step of Figure 13f, but without intermediate details. The black dashed lines follow features, which acted as EU/SSCS plate boundaries sometimes during the formation of the SCS. To summarize, opening started in the east sub-basin, east of Macclesfield Bank (Figure 14b), then extended north of Macclesfield Bank and in the Xisha trough (Figure 14c) and then possibly in the east sub-basin and south of the Macclesfield bank in direction of the Phu Khanh basin (Figure 14d). 
Figure 15: Structural map of the South China Sea (SCS) replaced in the general SE Asia background established from Pubellier et al. (2015). The paleo-suture of the proto-SCS (thick light grey line with triangles) is located south of Palawan and in north Borneo. The dark grey lines in the Xisha trough and Hoang Sa basin and possibly south of the Macclesfield bank and in the Phu Khanh basin are EU/SSCS tensional plate boundaries active during Early Oligocene. They follow rifted basins where normal faults (red lines) curve southward at the contact with the Qui Nhon ridge, showing that limited dextral motion occurred along the Qui Nhon ridge. From late Oligocene to middle Miocene, the western SSCS/EU plate boundary is connected to the subducting proto-SCS and jumped westward several times from the Ulugan fault to the western limit of the oceanic southwest sub-basin. Periods of ages given for each of the four segments of the southern margin are the periods during which such a segment moved southward along the fault located west of this segment. Note that the onset of oceanic crust for the conjugate segment of northern Palawan (Tainan segment) is $33 \mathrm{Ma}$ (IODP Preliminary Report, 2014) and is similar to the breakup unconformity onset in the NW Palawan basin. On the northern south China continental shelf, the Paleocene-Eocene rifted basins appear in light orange from the Luzon Ryukyu transform plate boundary (LRTPB) to the Songhong basin. East of the LRTPB, the continental shelf backarc basins appear in dark orange. Legend and colors in the SCS as in Figure 10.

Figure 16: Breakup or end-rift unconformities (BU or ERU) around the South China Sea from different sources (modified from Franke (2014)). PRMB, Pearl River Mouth basin; QDNB, Qiongdongnan (Hoang Sa) basin. Sea level curves after Haq et al. (1987) and Yubo et al. (2011). Ages of the onset of BU or ERU are indicated in red under each column. Note the decreasing ages of BU or ERU from east to west along the southern SCS continental margin, which is coherent with the plate kinematic sketches of Figure 13. 

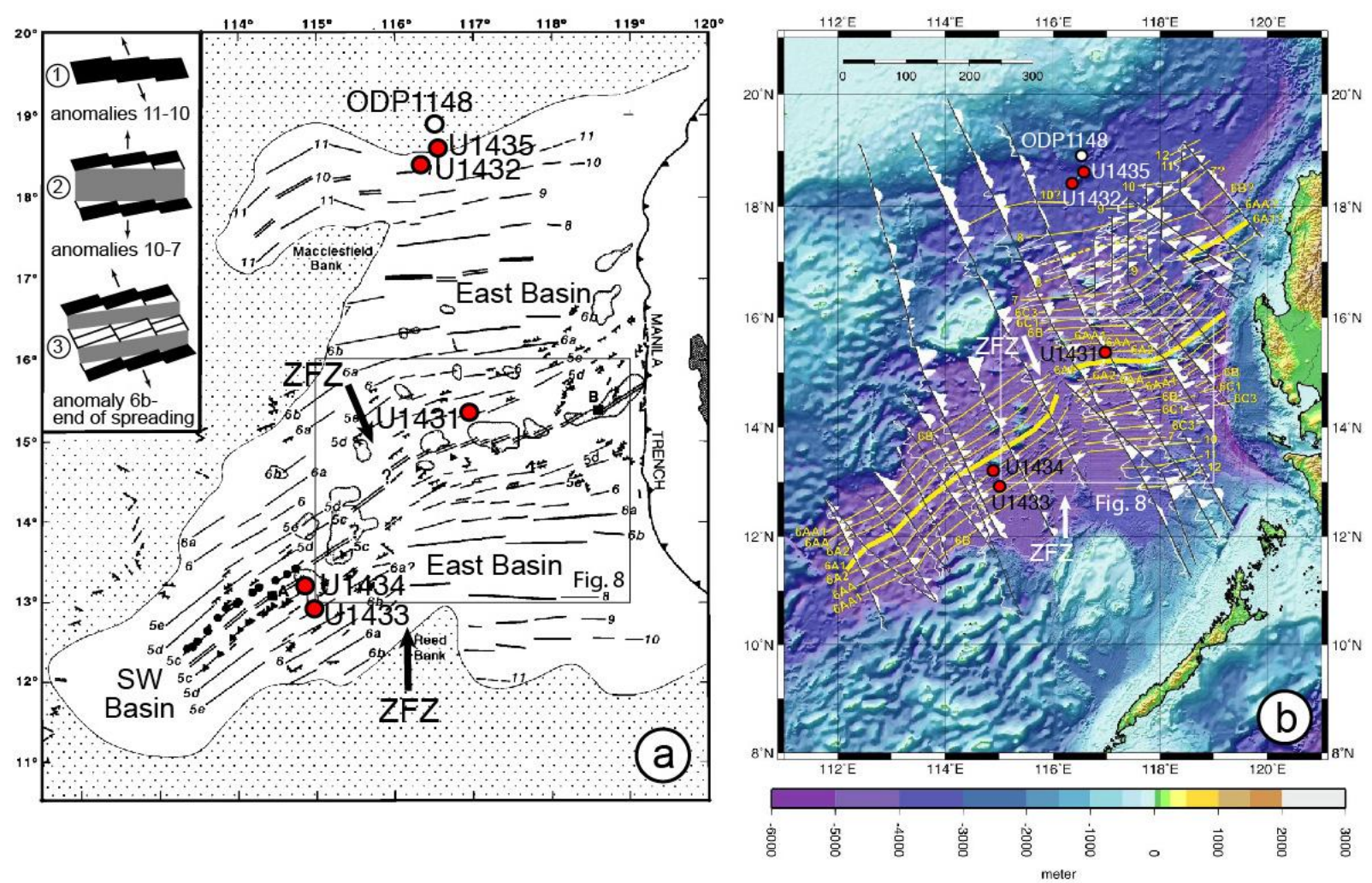

Figure 1: Magnetic lineations in the South China Sea (SCS). a) From Briais et al. (1993) with inset presenting the evolution of seafloor spreading geometry in the east sub-basin. b) SCS bathymetric map with magnetic profiles shown as wiggles along ship tracks and magnetic anomaly interpretation (thin yellow lines) from Barckhausen et al. (2014). Thick yellow lines are abandoned spreading ridges and numbers indicate magnetic chrons. ODP Site 1148 (white dot) and Leg 349 IODP Sites (red dots) are indicated. 


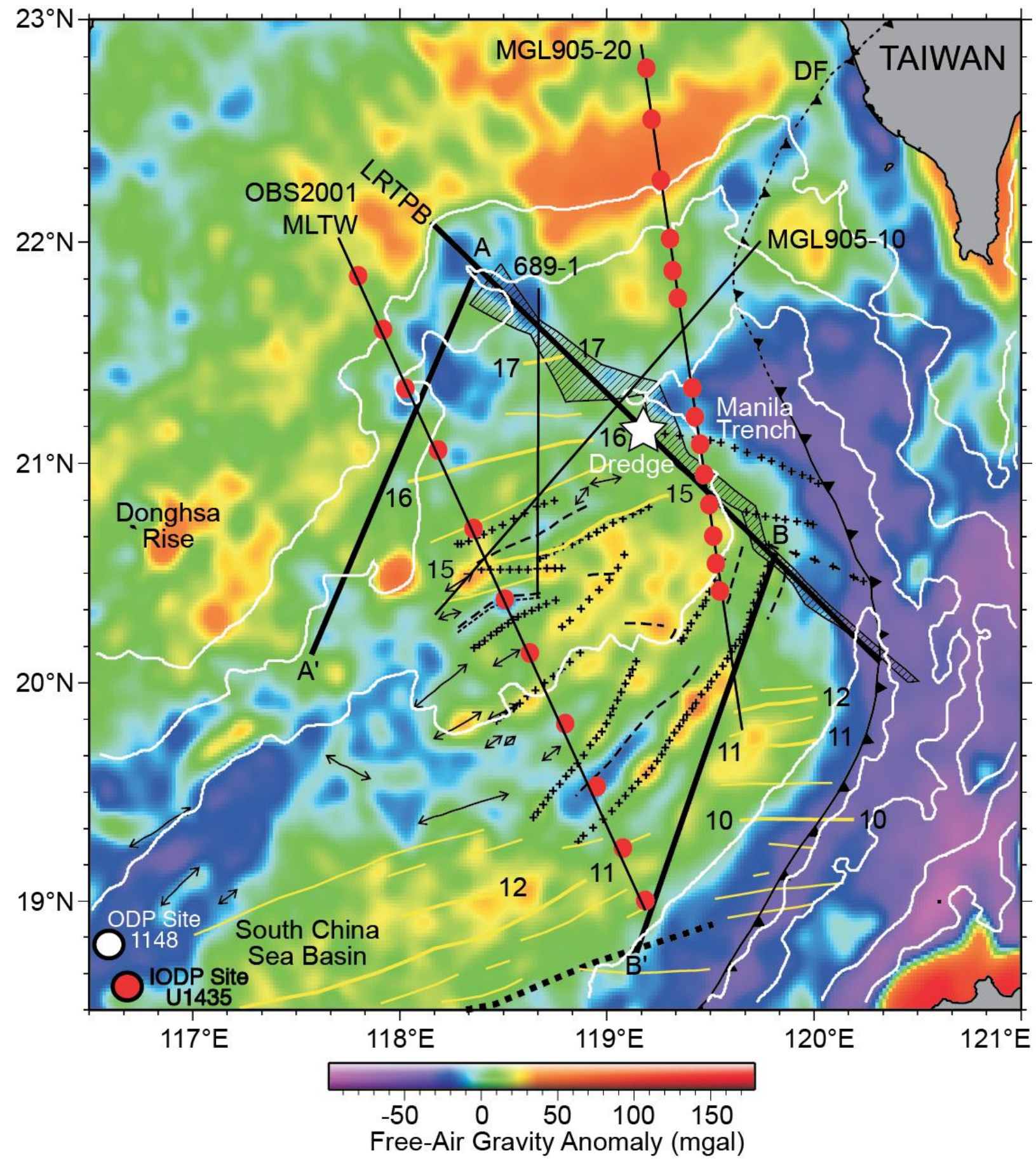

Figure 2: Free-air gravity map of the northeastern SCS showing chrons 15 to 17 (thick yellow lines) (Hsu et al., 2004) inside the domain bounded by AA', BB' and the Luzon-Ryukyu transform plate boundary (LRTPB) defined by the hachured area. White thin lines, bathymetric contours every $\mathrm{km}$. Black crosses and dashed black lines, structural highs (elongated volcanic intrusions) and elongated depressions established from seismic data. Thick black dashed line, change in seafloor spreading direction. Thin black lines with double arrows, ridge axes determined from swath-bathymetric data (Yeh et al., 2010). To the south, chrons C12 and younger (Briais et al., 1993). MCS lines and refraction lines OBS2001 and MGL905-20 (black lines) with locations of OBSs (red dots). White star, dredging location where basalts were dated $22 \mathrm{Ma}$ (Hsu et al., 2004). 

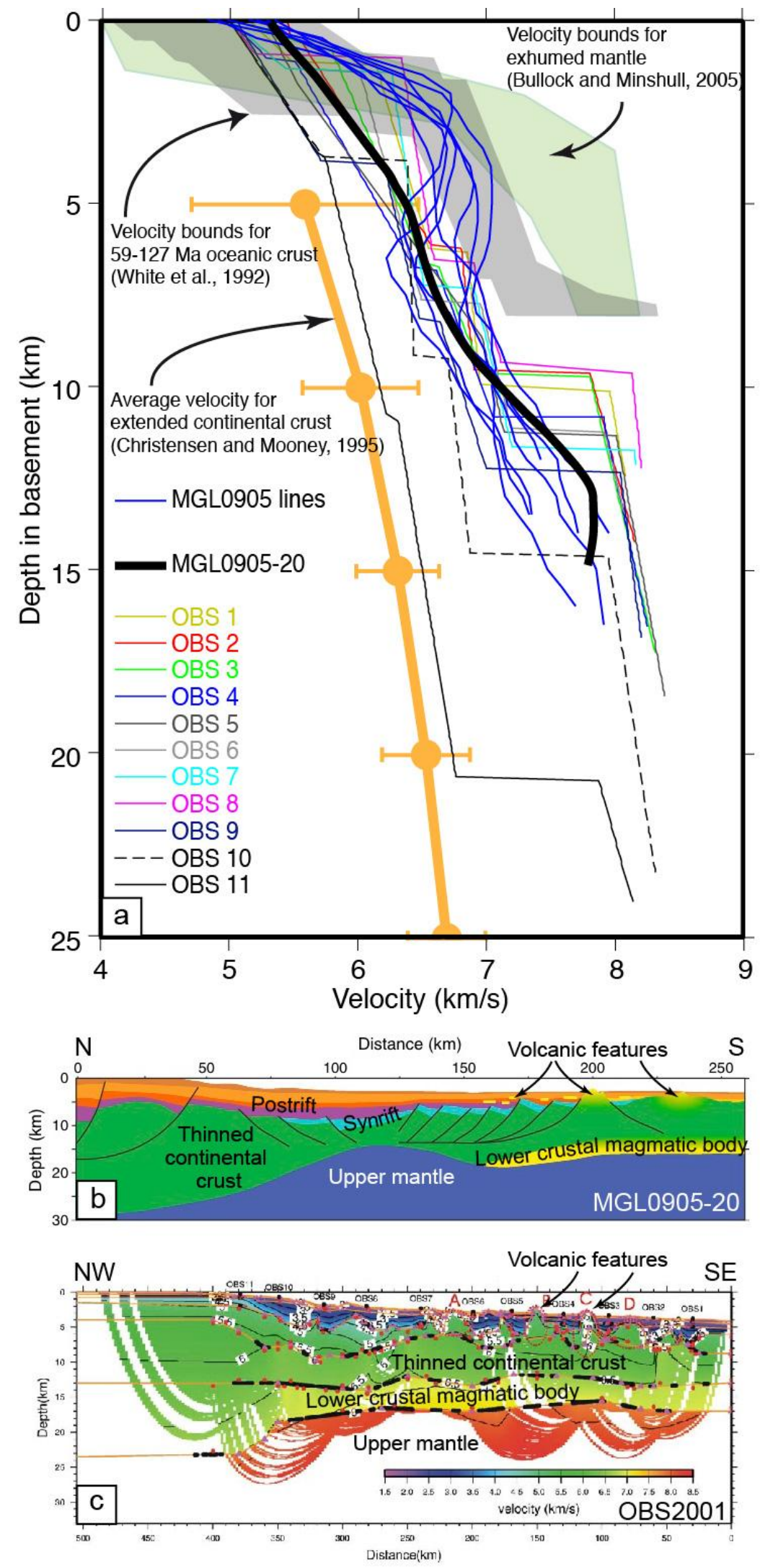

Figure 3: a) Velocity-depth profiles along lines OBS2001 (Wang et al., 2006) (OBSs 1 to 11), MGL905-20 (thick black line) (Lester et al., 2014) and MCS stack velocities (in blue) from portions of lines MGL0905-3, 4, $5,10,20,25 \mathrm{~A}$ located inside the domain bounded by AA', BB' and the LRTPB (lines MGL0905-10 and 20 are located in Figure 1, other lines in Yeh et al. (2010)). The area in grey indicates the velocity bounds for normal oceanic crust aged 59-144 Ma (White et al., 1992); the area in light green shows the bounds of velocity-depth profiles through the zone of exhumed mantle west of Iberia (Bullock and Minshull, 2005); the orange thick line is the average velocity curve for extended continental crust with horizontal bars representing \pm 1 standard deviation (Christensen and Mooney, 1995). P-wave velocity models along profiles MGL905-20 (Lester et al., 2014) (b) and OBS2001 (Wang et al., 2006) (OBSs 1 to 11) (c). A, B, C and D are buried or outcropping volcanic ridges. 

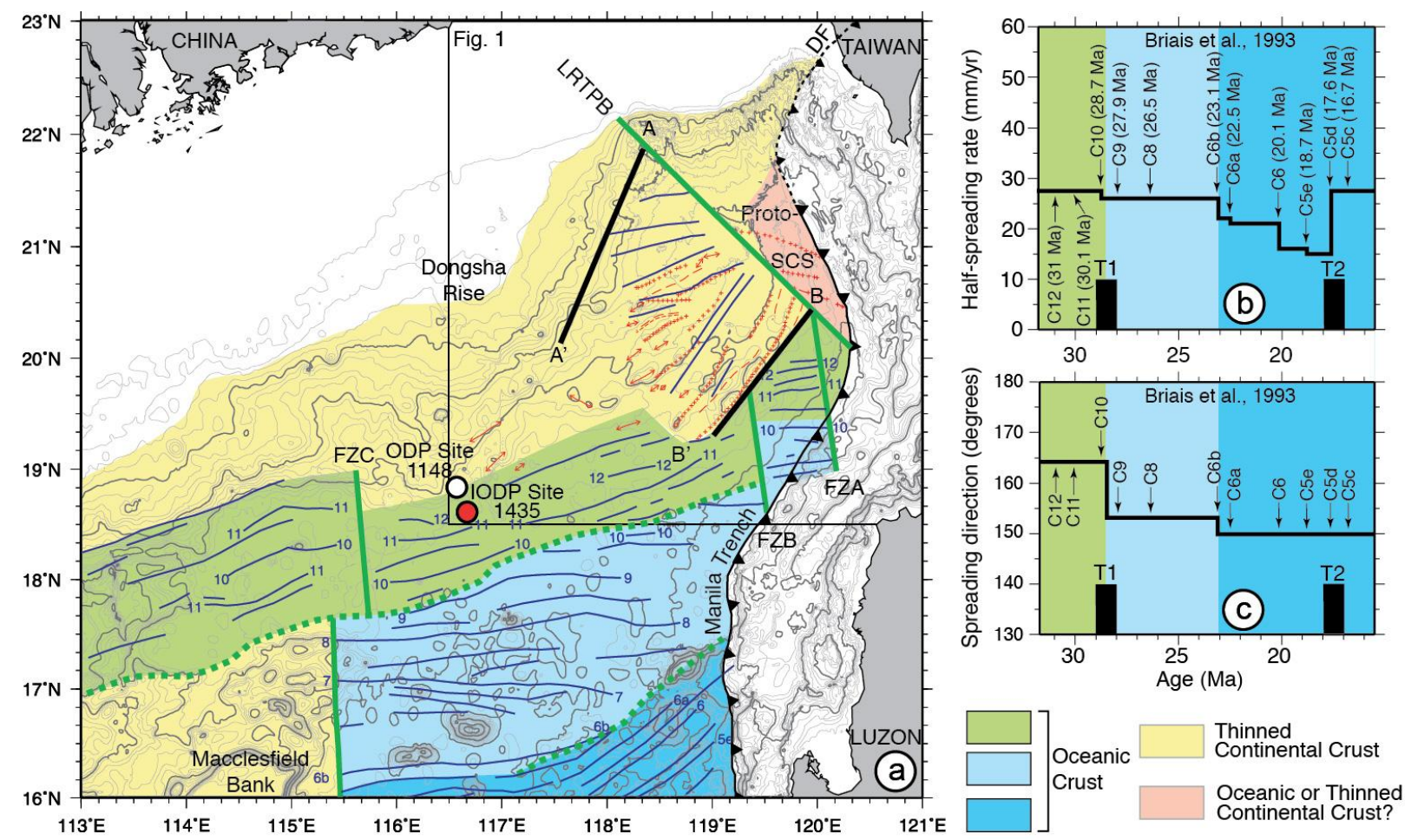

Figure 4: Structural framework of the northeastern South China Sea (SCS), magnetic lineations and half-spreading rates modified from Briais et al. (1993). a) Bathymetry every $200 \mathrm{~m}$ in grey and every $1000 \mathrm{~m}$ in dark grey. Dark blue lines, magnetic lineations adapted from Briais et al. (1993); thick green lines, FZs; dotted thick green lines, ridge jumps; red crosses and dashed red lines, elongated structural highs and depressions established from seismic data. Green, light blue and dark blue are oceanic domains formed during kinematic phases marked by changes in spreading rates, spreading directions or both (Briais et al., 1993). Yellow, thinned continental crust; light pink, proto-SCS, which is oceanic or thinned continental crust. DF, deformation front. b) Half-spreading rates in the northeastern SCS calculated from chron C12 to 15.5 Ma by using Briais et al. (1993) synthetic magnetic models with the Gradstein et al. (2004) time-scale. T1 is an extensional tectonic phase and T2 is associated with the emplacement of volcanic ridges located between AA', BB' and the LRTPB. c) Spreading directions are calculated by assuming that they are perpendicular to the trends of magnetic lineations. 

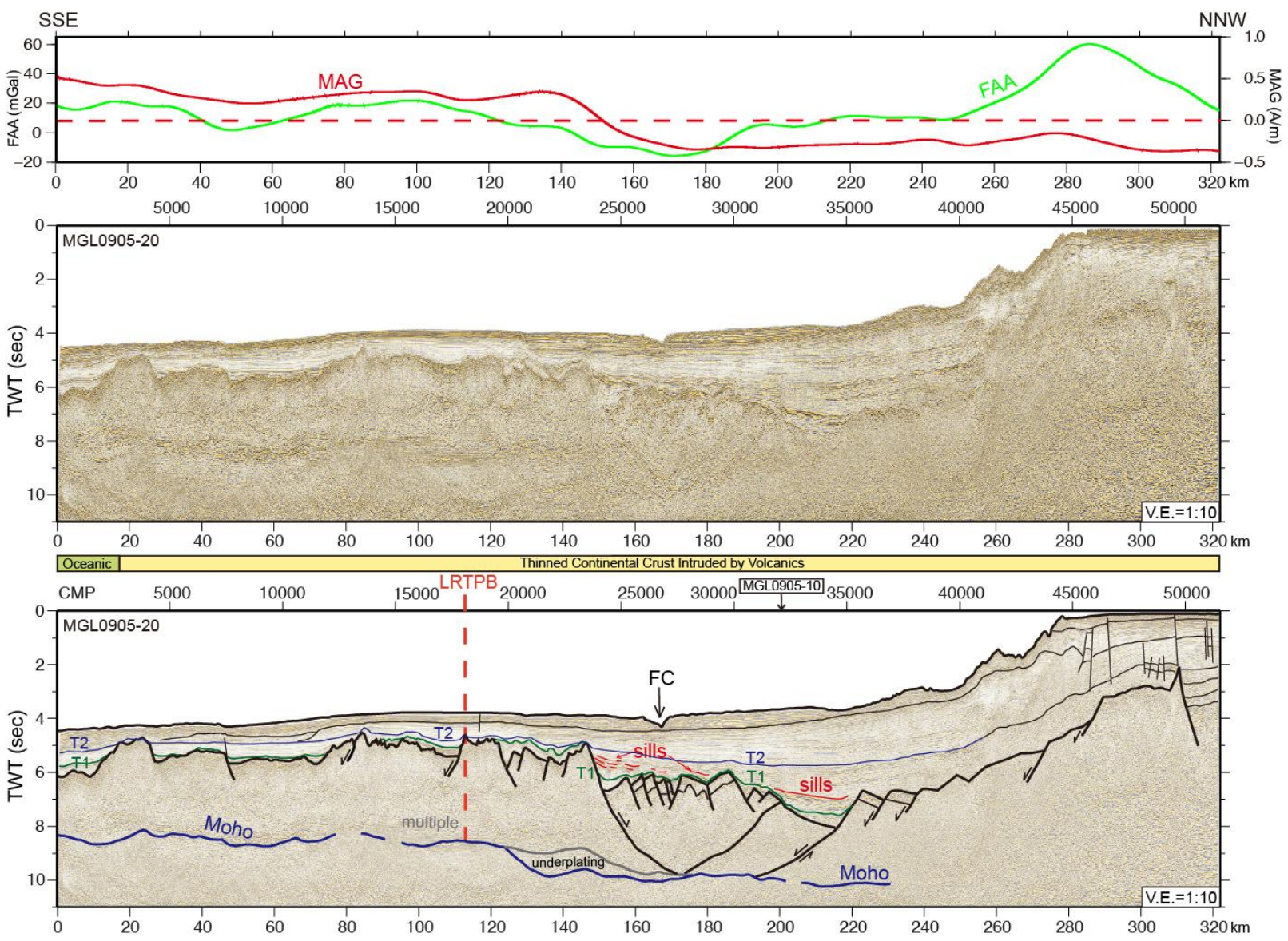

Figure 5: Revised interpretation of MCS profile MGL0905-20 (Yeh et al., 2012) located in Figure 1. Based on refraction results (Figure 2) and the interpretation of MCS data, the nature of the crust is thinned continental crust (in yellow) and oceanic (in light green) in the extreme southern part of the profile with some underplating at the base of the crust. Tectonic phases $\mathrm{T} 1$ and $\mathrm{T} 2$ are underlined by seismic unconformities (green and blue lines, respectively). The free-air gravity anomaly and inverted magnetization appear in the upper part of the figure (Yeh et al., 2012). Sills are present between unconformities T1 and T2. FC, Formosa Canyon. 

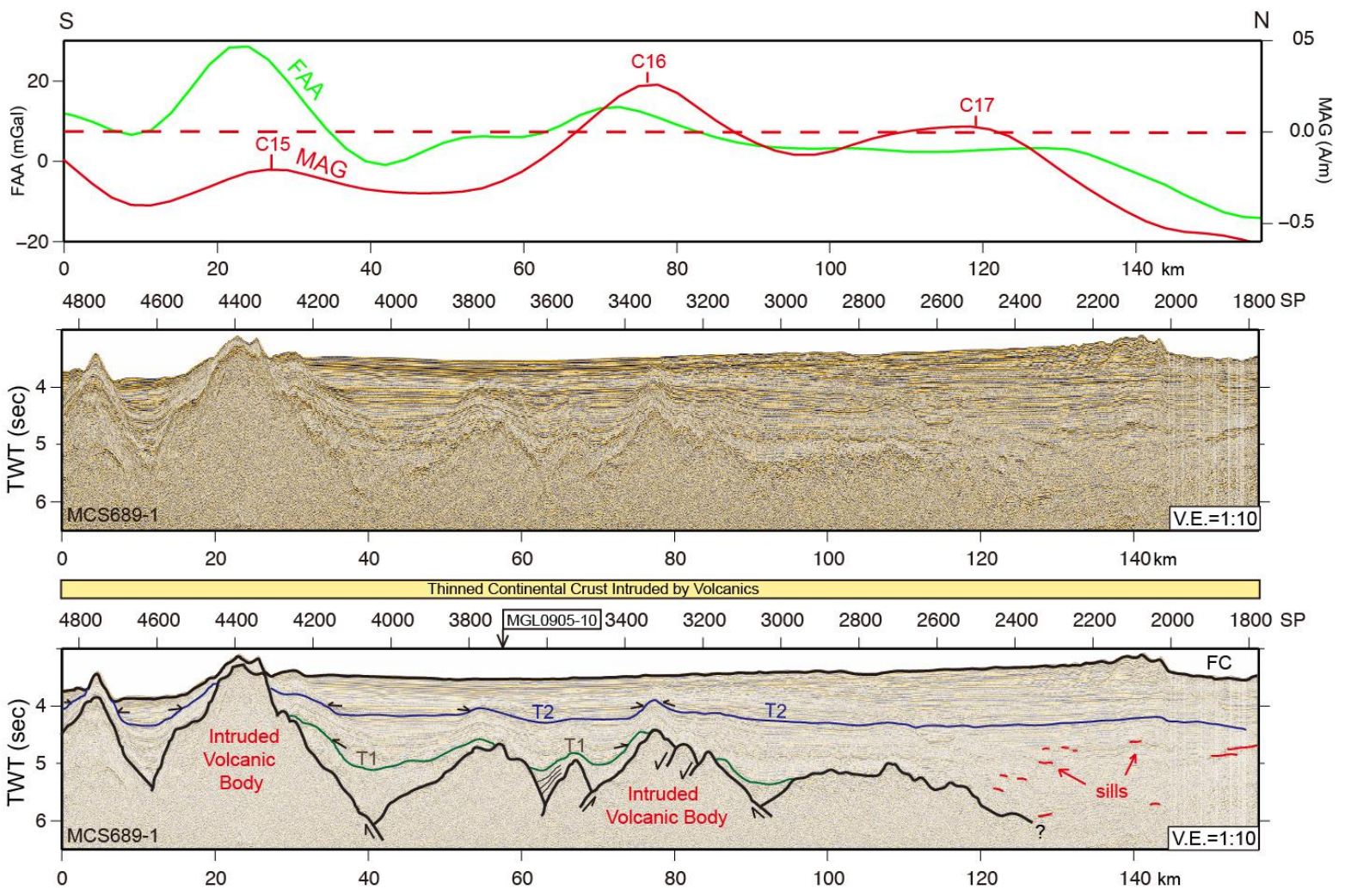

Figure 6: Revised interpretation of MCS profile MCS689-1 (Yeh et al., 2012). The profile is perpendicular to magnetic lineations trends identified as chrons C15-C17 (Hsu et al., 2004) and shown here as magnetization anomalies (Yeh et al., 2012). These magnetic lineations are associated with volcanic features intruded through the thinned continental crust as shown by refraction results. Overlying sediments were uplifted up to the T2 unconformity (early Miocene) showing that magnetic lineations $\mathrm{C} 15$ to $\mathrm{C} 17$ are not seafloor spreading lineations. 

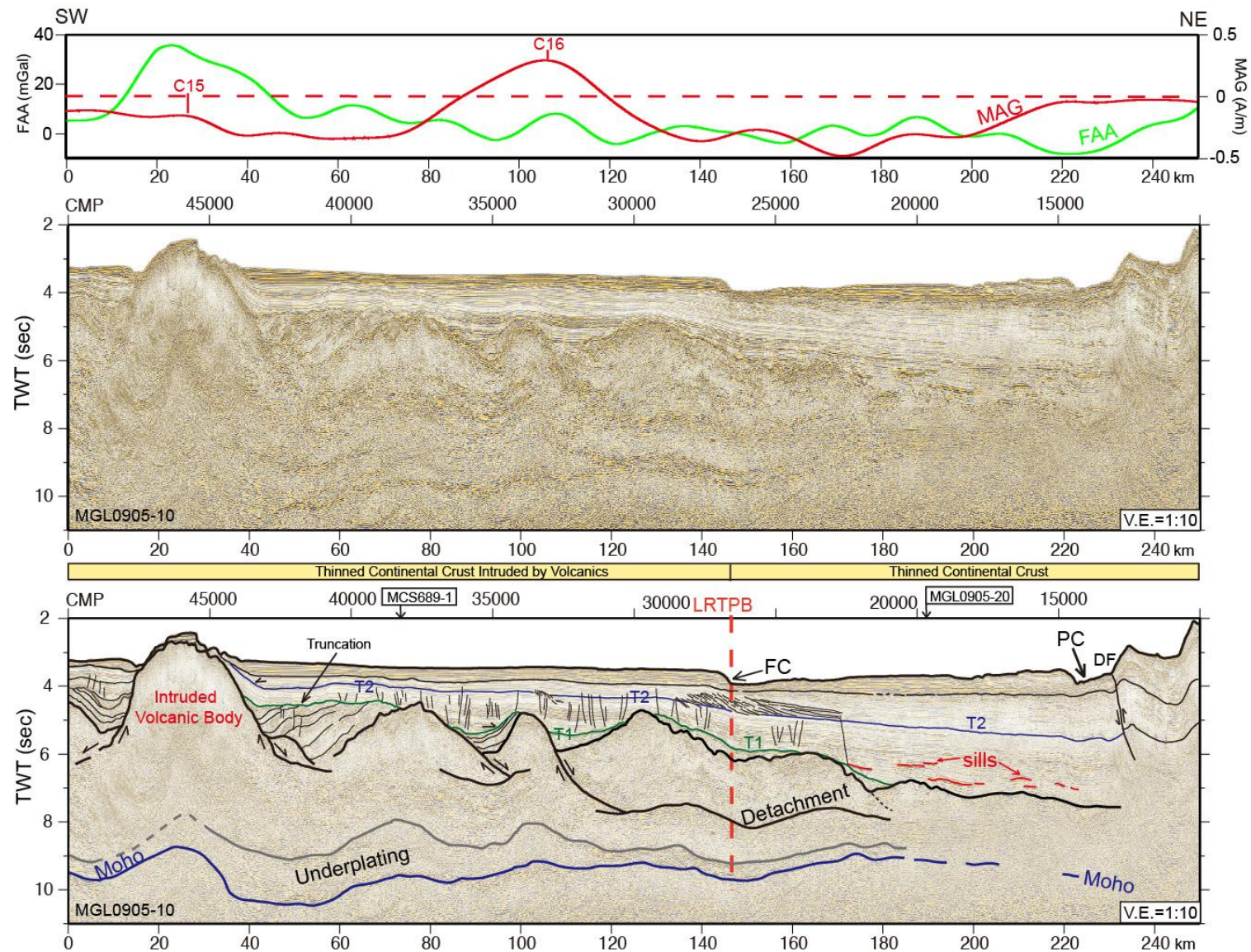

Figure 7: Post-stack time migration of MCS profile MGL0905-10 (Yeh et al., 2012) and revised interpretation. The profile cut across magnetic lineations identified as chrons $C 15$ and $C 16$ (Hsu et al., 2004). These magnetic lineations (Figure 1) are associated with volcanic features, which have uplifted already deposited sediments up to the T2 unconformity. North of the LRTPB, below the proto-SCS, the underplating is still present but disappears northeast of CMP20000. From refraction results, the nature of the crust is thinned continental crust. Sills are present between unconformities T1 and T2. FC, Formosa canyon; PC, Penghu canyon; DF deformation front. 


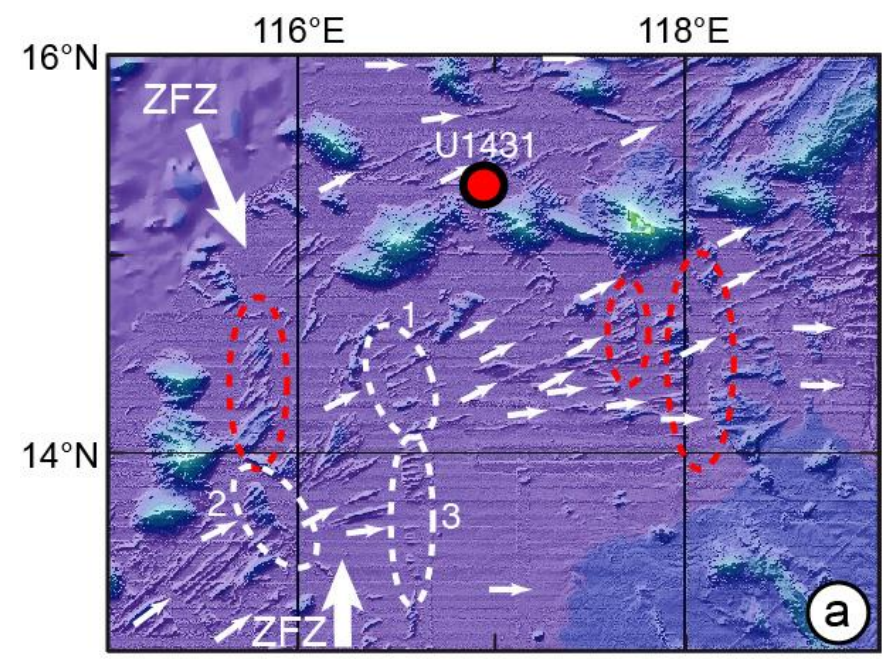

Swath-bathymetry

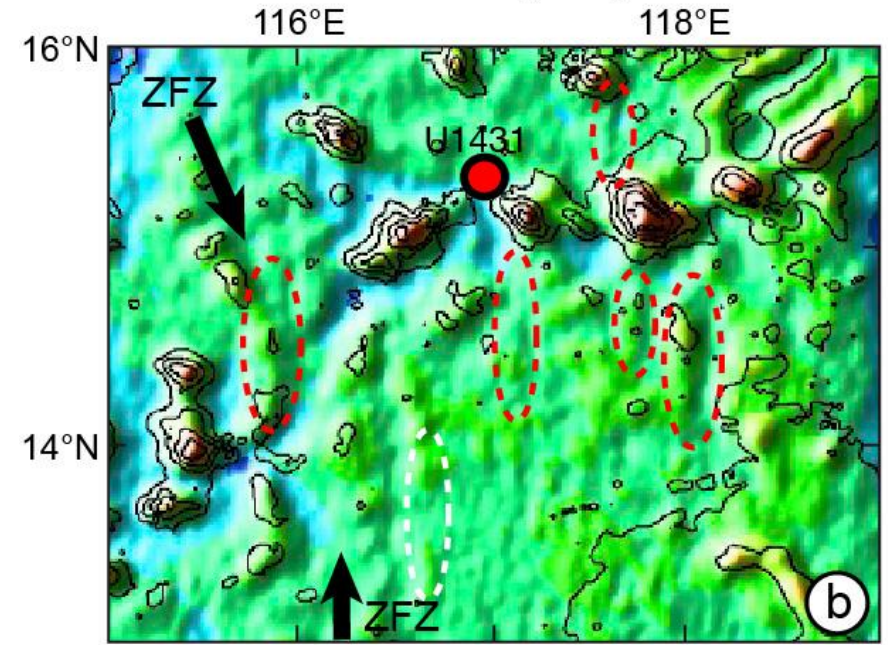

Free-air gravity anomalies

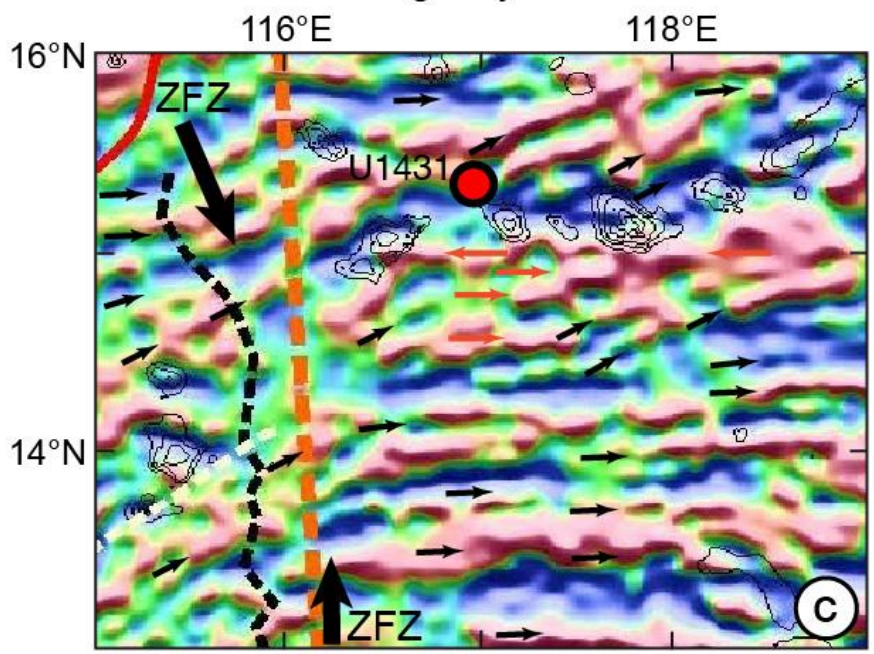

magnetic anomalies
Figure 8: Detailed swath-bathymetric map (Barckhausen et al., 2014), free-air gravity map (Sandwell et al., 2014) with superimposed bathymetry and contoured magnetic anomalies (Ishihara and Kisimoto, 1996) located in Figure 1, in the central part of the South China Sea (SCS), on each side of the Zhongnan faults zone (ZFZ). Red dot, Leg 349 IODP Site U1431. a) White arrows points toward the seafloor spreading lineaments and are trending differently in the axial part of Figure 8a than outside of it. Red ovals underline uplifted seafloor spreading features during the N-S post-spreading extension. Note that seafloor-spreading features are not perpendicular to the N-S post-spreading fabric features. White ovals (1, 2 and 3 ) underline non-uplifted seafloor spreading features of the spreading fabric, which are associated to perpendicular FZs belonging to the spreading fabric. b) Red ovals underline N-S post-spreading features which are clearly oblique to the $\mathrm{N} 055^{\circ}$ seafloor spreading fabric and the $\mathrm{N} 145^{\circ} \mathrm{FZ}$ features of the spreading fabric shown in Figure 8a. The white oval underlines a non-uplifted seafloor spreading features of the spreading fabric and the associated perpendicular $\mathrm{FZs}$ belonging to the spreading fabric but it is extremely difficult to separate a N-S post-spreading features from a FZ of the spreading fabric, which also trends roughly N-S outside the central area. c) Black arrows point toward the direction of magnetic lineations of the spreading fabric and are trending roughly E-W outside of the central part of Figure 8c. These seafloor spreading directions are exactly the same as in Figure 8a but we must notice that in the axial part of the SCS, many E-W trending lineations (red arrows) of the post-spreading fabric obliterate the $\mathrm{N} 55^{\circ}$ spreading fabric. 


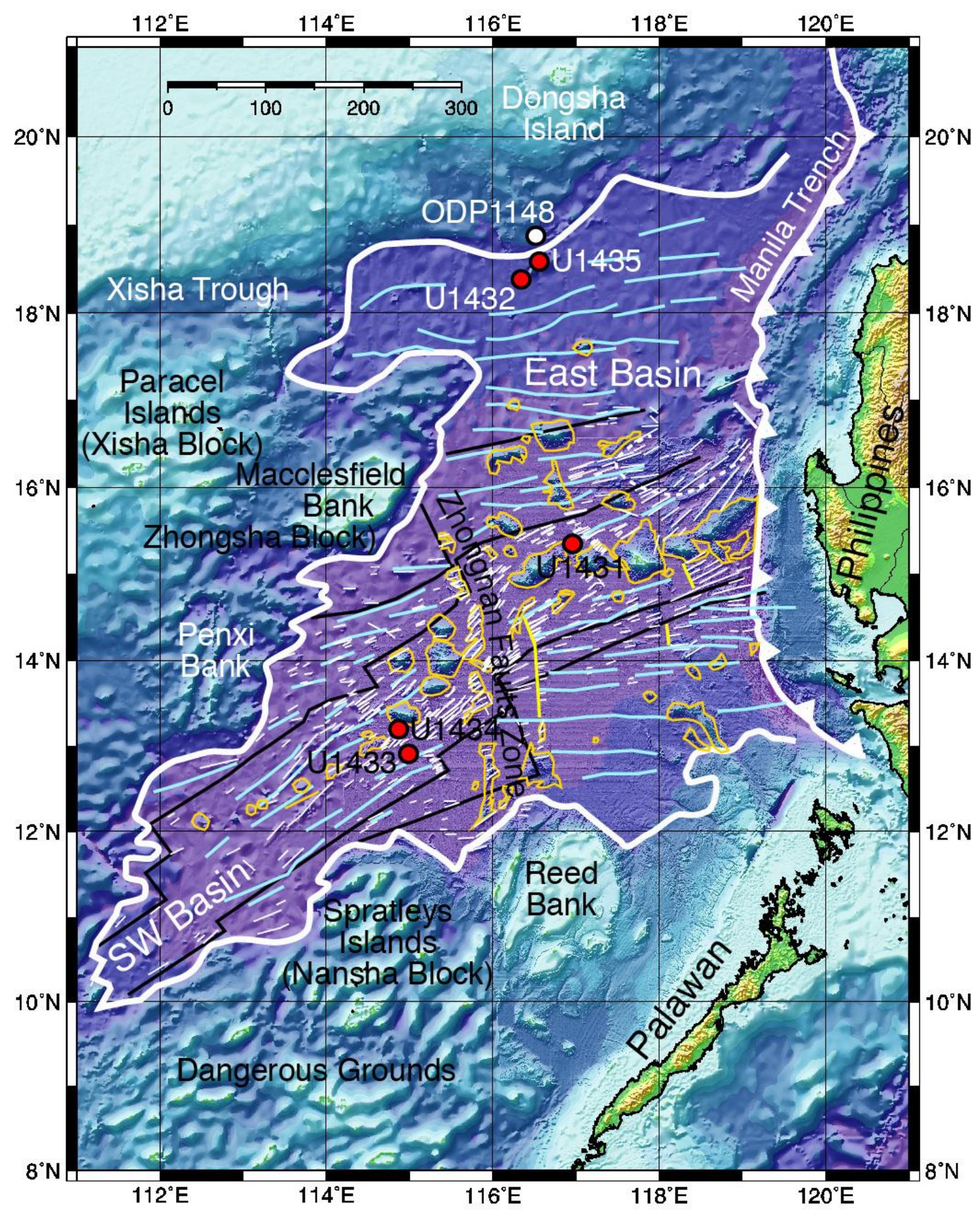

Figure 9: Bathymetric map of the South China Sea (SCS) (Barckhausen et al., 2014), with observed seafloor spreading lineaments (thin white segments) and FZs of the spreading fabric (thin yellow segments) extracted from available published swath-bathymetric maps, well-expressed negative magnetic lineations (light blue segments) extracted from the magnetic anomaly contoured map (Ishihara and Kisimoto, 1996) and post-rift volcanism (brown continuous lines) extracted from available published swath-bathymetric maps. The continent-ocean boundary (thick white line) was established following Cameselle et al. (2015) for the SCS northwestern margin, Li et al. (2015) and Ding and Li (2011) for the rest of the SCS. The Manila trench (thick white line with triangles) bounds the oceanic portion of the SCS. Black lines bound domains with different seafloor spreading trends. 


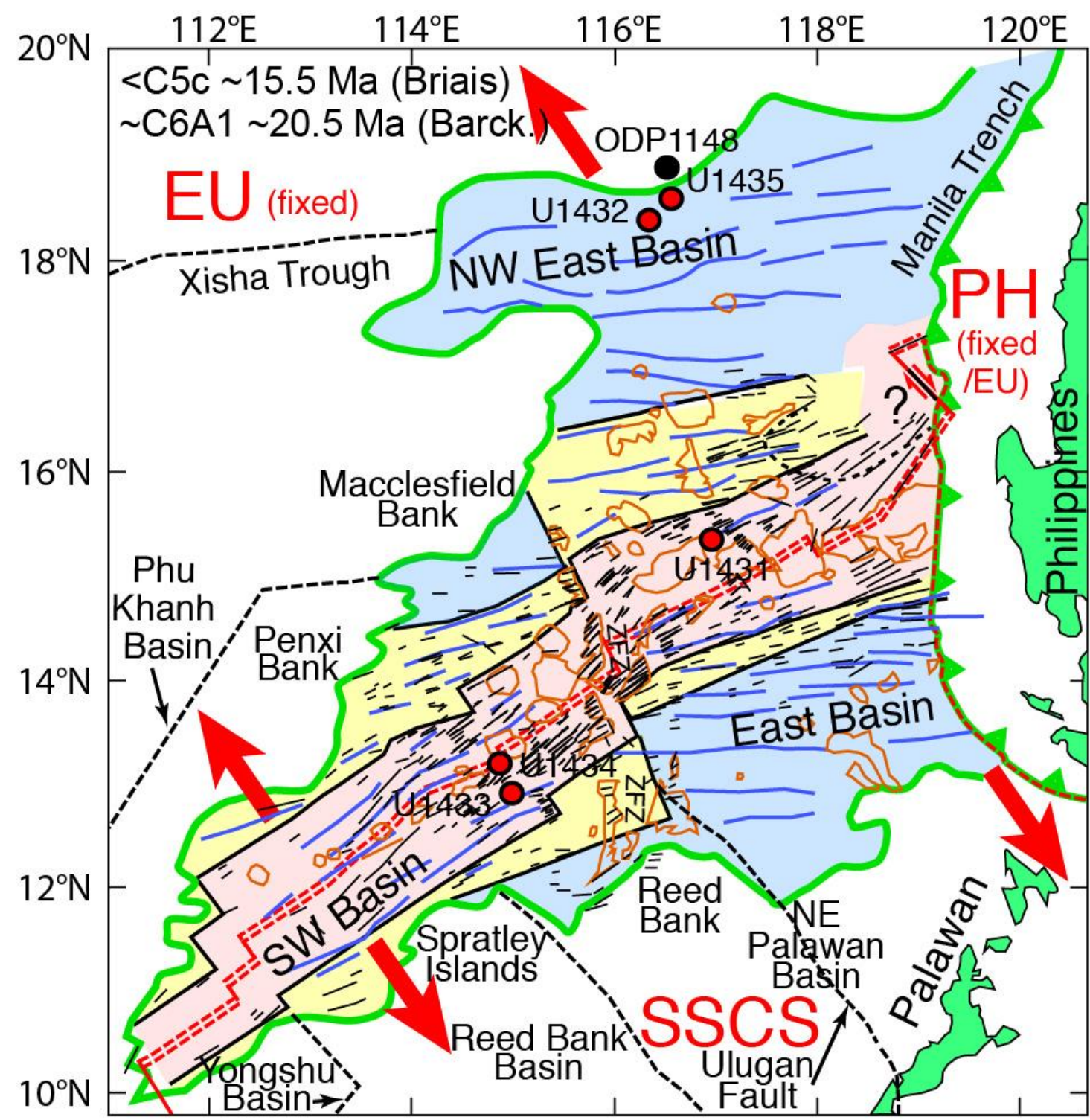

$\square$ N145 extension $\square$ N165 extension $\square$ N175 extension

C Post-spreading volcanism .....- Recent extension \# Rift directions

Magnetic directions Manila trench $\longrightarrow$ COB

====== Present ridge axis $\bullet$ Drill holes $\longleftrightarrow$ Direction of extension ------ Plate boundary ------ Former plate boundary

Figure 10: Summary of observed seafloor spreading trends in the South China Sea (SCS) extracted from Figure 9. Black lines bound domains with different seafloor spreading trends: the pink domain with $\mathrm{N}^{\circ} 55^{\circ}$ trends, the yellow domain with $\mathrm{N} 075^{\circ}$ trends, the blue domain with $\mathrm{N} 085^{\circ}$ trends. Large red arrows show the direction of extension during the formation of the pink domain. The outline of the

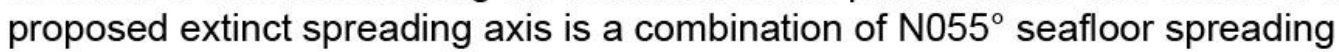
trends and $\mathrm{N} 145^{\circ} \mathrm{FZs}$ but is still preliminary. The black dashed lines are features, which acted as plate boundaries during the formation of the SCS. ZFZ, Zhongnan faults zone; EU, PH and SSCS are Eurasia, Philippine Sea and Southern South China Sea plates respectively. 


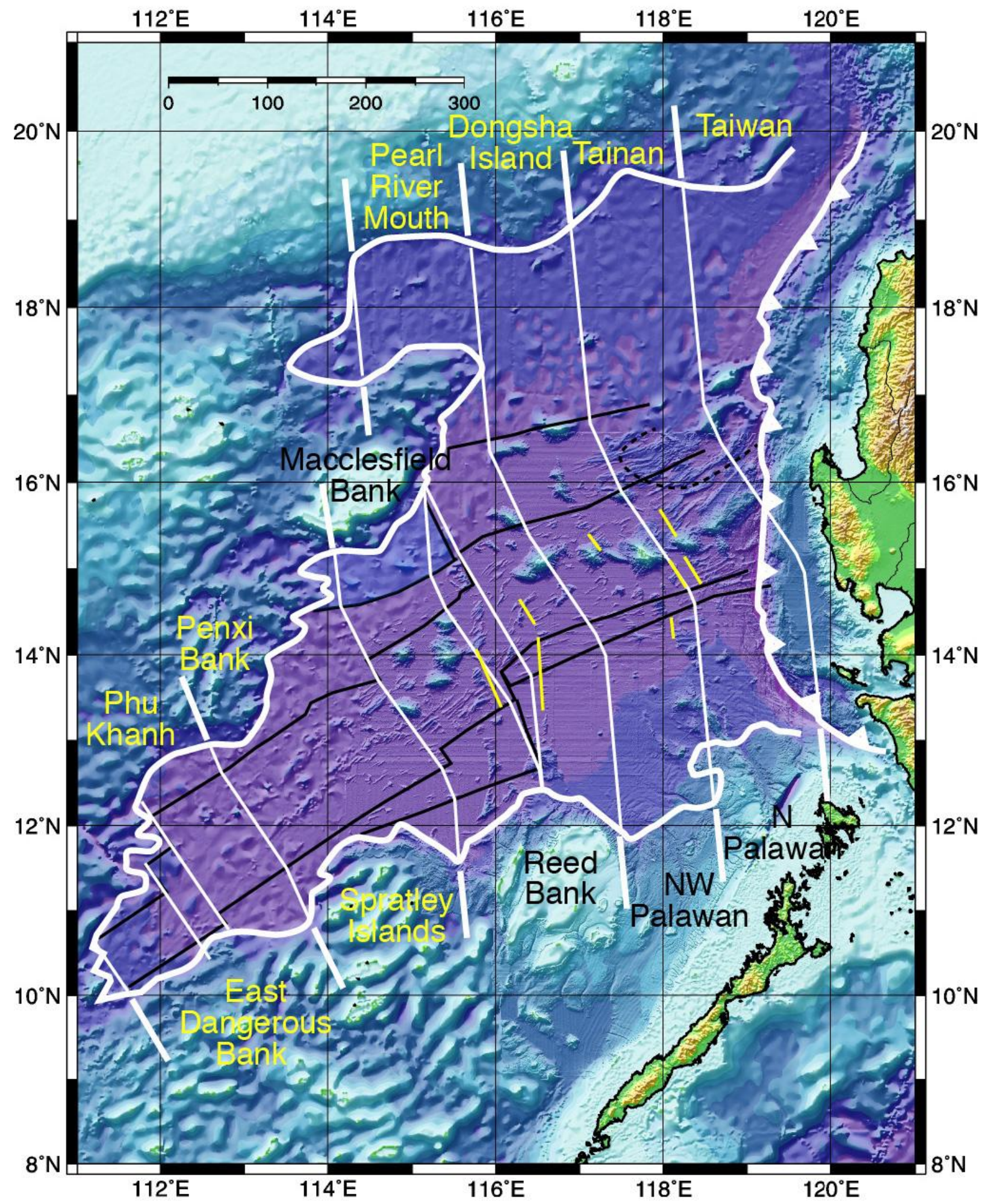

Figure 11: Bathymetric map of the South China Sea (SCS) (Barckhausen et al., 2014) with observed FZs of the spreading fabric (thin yellow segments). The continent-ocean boundary (thick white line) and the Manila trench (thick white line with triangles) bound the oceanic portion of the SCS. Black lines bound domains with different seafloor spreading trends as shown in Figure 10. The kinematic flow lines (thin white lines) show conjugate segments of passive margins located north and south of the SCS, with their names on each side of the SCS. 


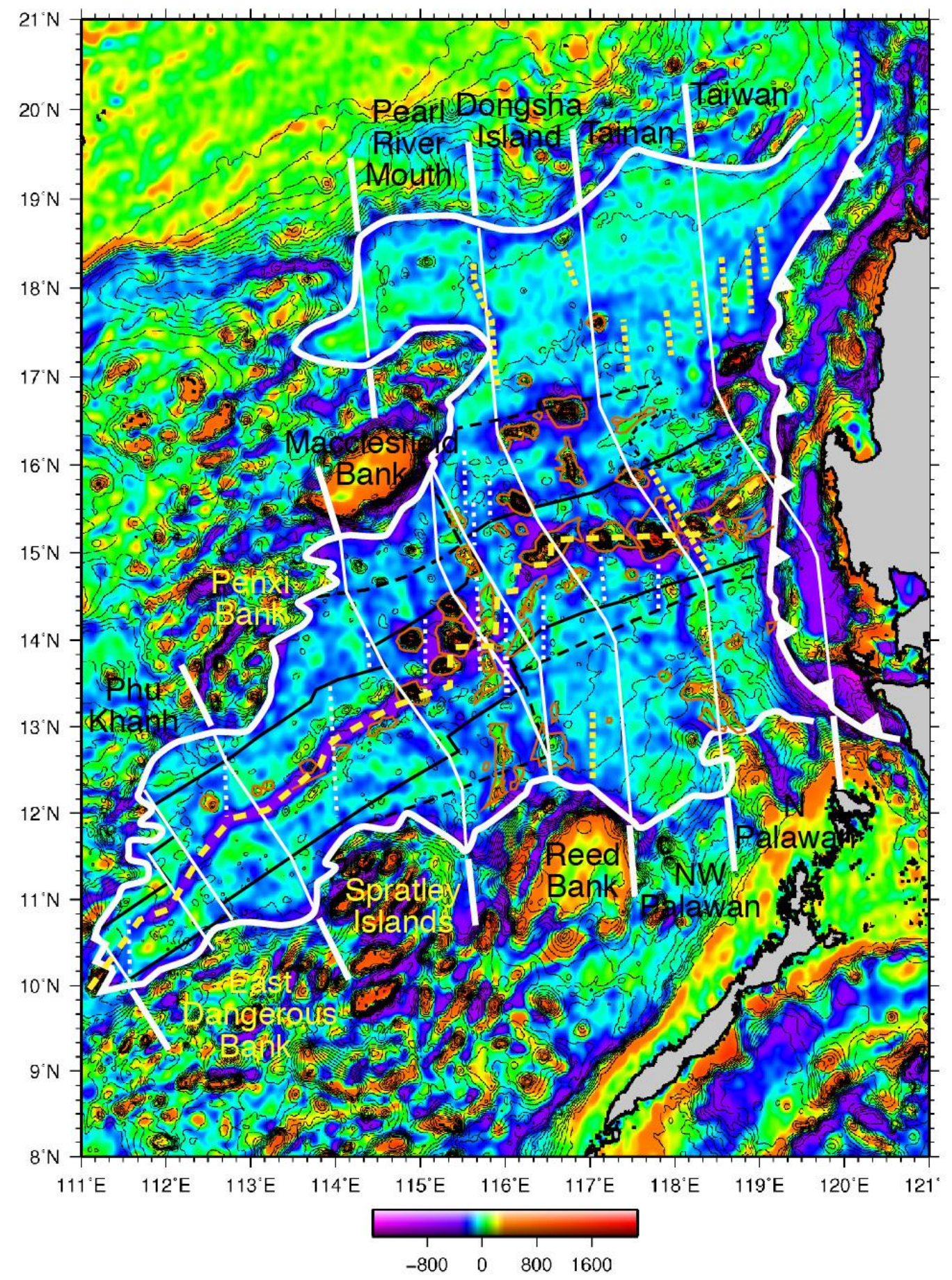

Bouguer Gravity Anomaly (mGal)

Figure 12: Bouguer anomaly map computed from the free-air gravity map (Sandwell et al., 2014) with superimposed bathymetric contours. The 3D Bouguer anomaly map was computed with assigned densities of 1.03 and $2.3 \mathrm{~g} / \mathrm{cm} 3$ for water and sediments respectively. The color scale ranges from -200 to $+200 \mathrm{mGal}$. The thick white line is the continent-ocean boundary $(\mathrm{COB})$ and the thick white line with triangles the Manila trench. Brown contours underline the post-spreading volcanism as already suggested (Barckhausen et al., 2014). Negative Bouguer gravity anomalies (yellow large dahed line) underline the E-W line of post-spreading seamounts in the east sub-basin, which does not follow the $N 055^{\circ}$ seafloor spreading directions of the central part of the east sub-basin (Figure 10). In general, seafloor spreading lineaments and fracture zones (FZ, dotted yellow lines) are underlined in the Bouguer map inside the $\mathrm{N}^{\circ} 55^{\circ}, \mathrm{N}^{\circ} 75^{\circ}$ and $\mathrm{N} 085^{\circ}$ trending seafloor spreading lineaments observed in areas between continuous black lines, between dashed black lines and outside of dashed black lines, respectively. Numerous FZs underlined by yellow dotted lines and belonging to the oldest oceanic domain are parallel to the kinematic flow lines (thin white lines). The N-S white dotted lines underline the post-spreading N-S trends evidenced in the Bouguer gravity anomaly map only within the $N 055^{\circ}$ domain as already shown by bathymetric trends (Figure $8 \mathrm{a}$, red ovals) and within the Zhongnan faults zone. 

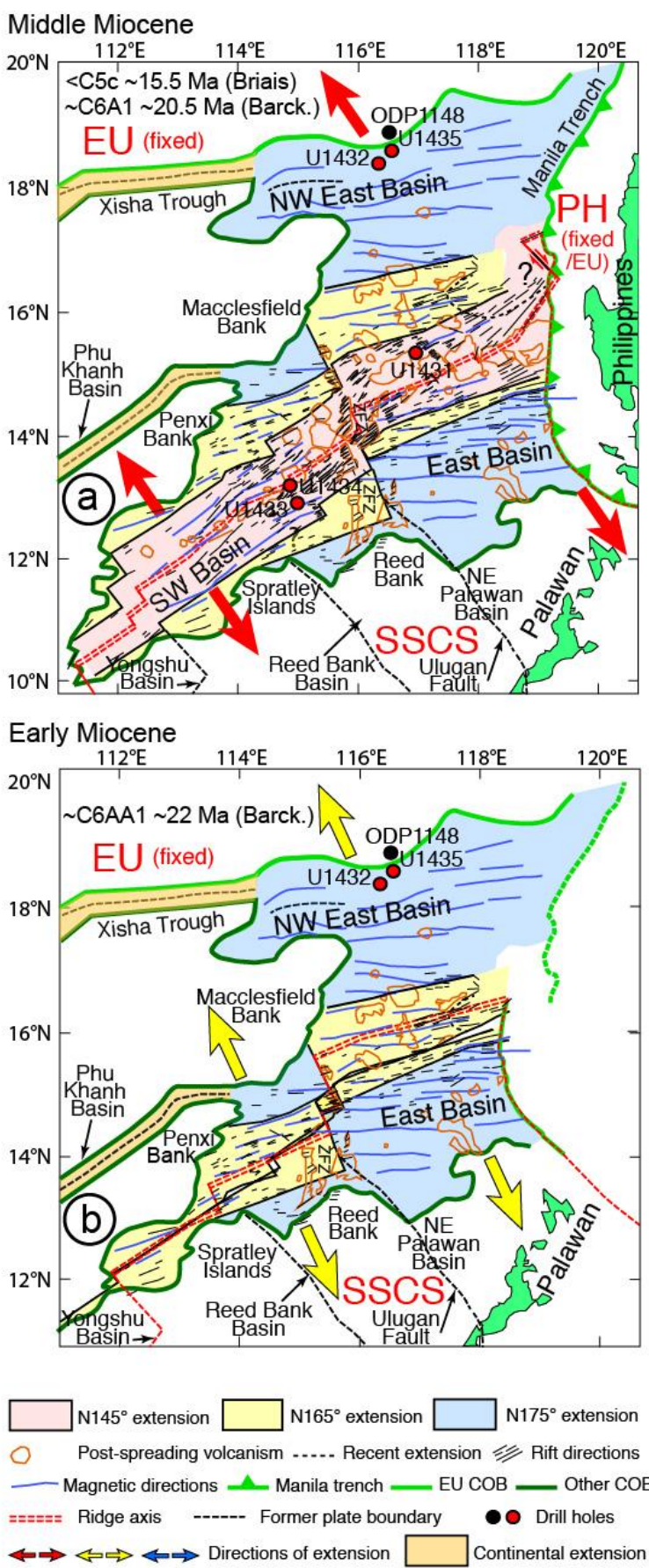
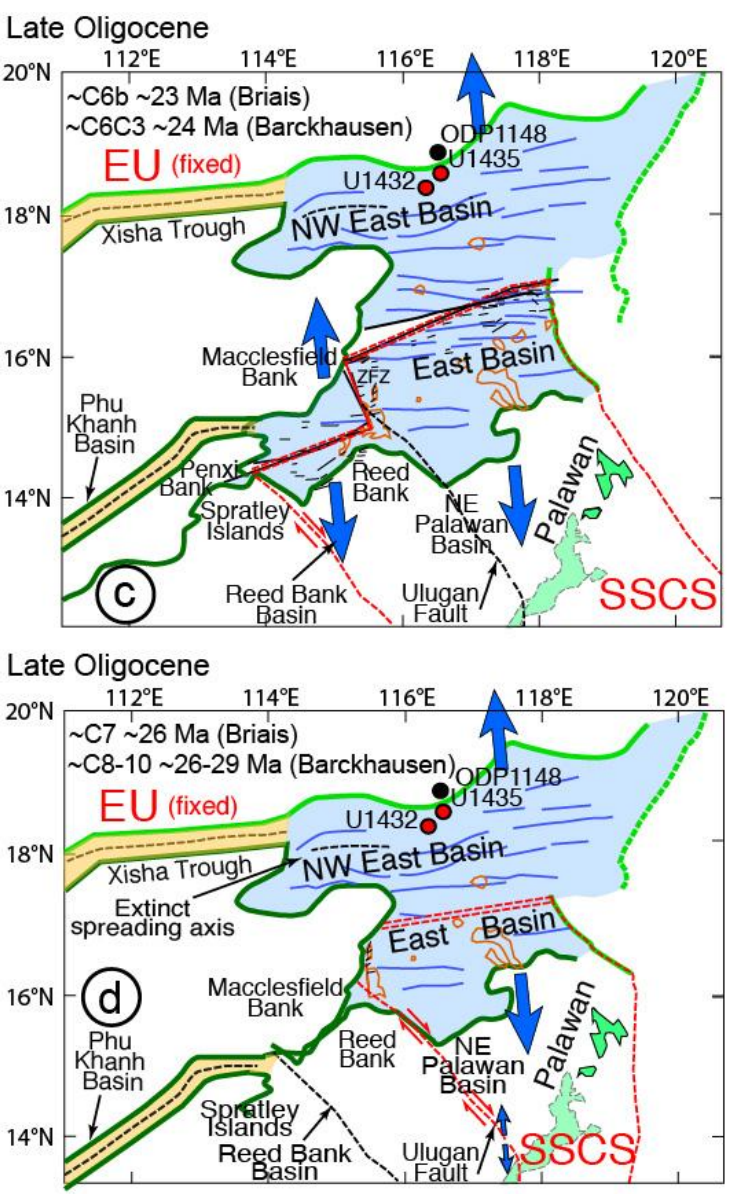

Early Oligocene
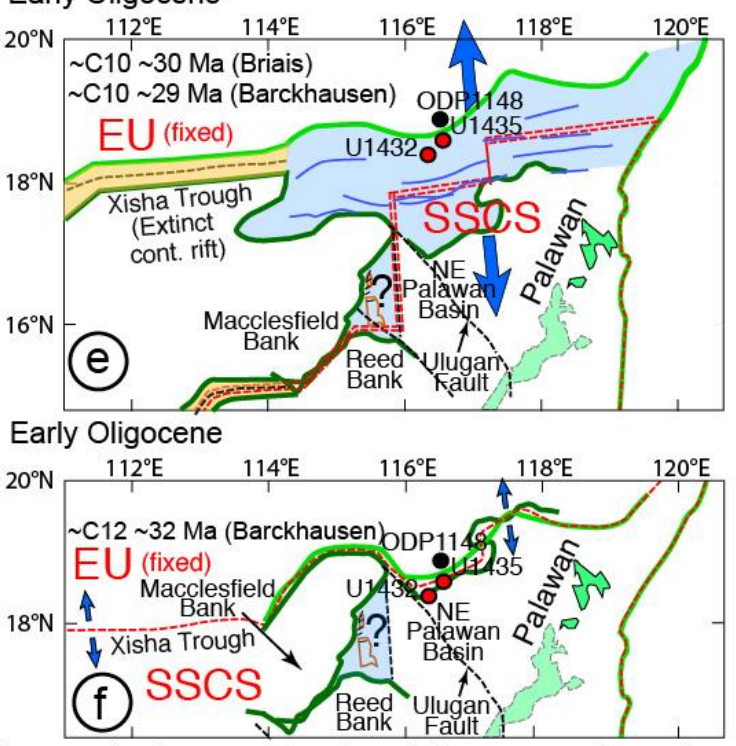

Figure 13: Plate kinematic reconstruction sketches of the South China Sea (SCS) at different epochs. Indications of time are given by comparison with ages of magnetic lineations of Briais et al. (1993) and Barckhausen et al. (2014) and by using their time scales. The large arrows give the directions of extension from the older stage to the considered stage. The plate boundary (in red) between the Eurasia (EU) and the southern SCS (SSCS) plates is given for all reconstructions before re-adjustment for the younger step. The eastern limit of the east sub-basin corresponds to the Manila trench. The black dashed lines are features, which acted as EU/SSCS plate boundaries at some stage during the SCS formation. They are important features to explain the step-by-step SCS opening in a broader context. ZFZ, Zhongnan faults zone. Central and south Palawan in dashed lines and light green before their formation by underthrusting of late Oligocene-early Miocene Nido limestones before the end of early Miocene (Aurelio et al., 2014; Steuer et al., 2014). 


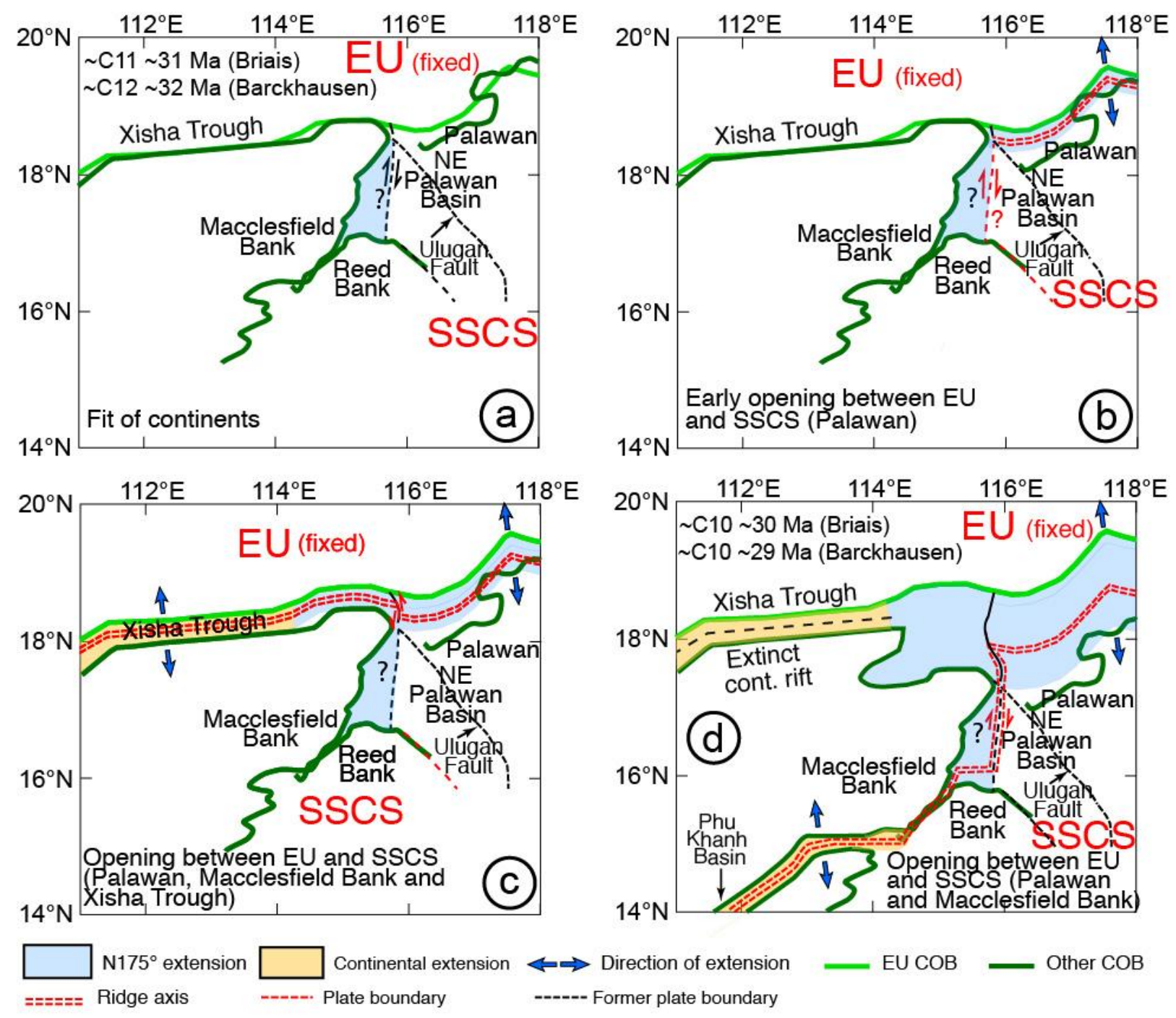

Figure 14: Tentative plate kinematic sketches of the early South China Sea (SCS) opening with two proposed new steps in between Figures $13 \mathrm{e}$ and $13 \mathrm{f}$. The small blue arrows give the directions of extension $\left(\mathrm{N} 175^{\circ}\right)$ since the closure. The plate boundary configuration (in red) between Eurasia (EU) and the southern SCS (SSCS) plates is given in figures $14 \mathrm{~b}$ to $14 \mathrm{~d}$, before any re-adjustment for the following younger step. For example, the seafloor spreading axis in Figure 14d was active from the step of Figure $14 \mathrm{c}$ to the step of Figure 14d. In contrast, the seafloor-spreading axis in Figure $13 \mathrm{e}$ was active from the step of Figure $13 \mathrm{e}$ to the step of Figure $13 \mathrm{f}$, but without intermediate details. The black dashed lines follow features, which acted as EU/SSCS plate boundaries sometimes during the formation of the SCS. To summarize, opening started in the east sub-basin, east of Macclesfield Bank (Figure 14b), then extended north of Macclesfield Bank and in the Xisha trough (Figure 14c) and then possibly in the east sub-basin and south of the Macclesfield bank in direction of the Phu Khanh basin (Figure 14d). 


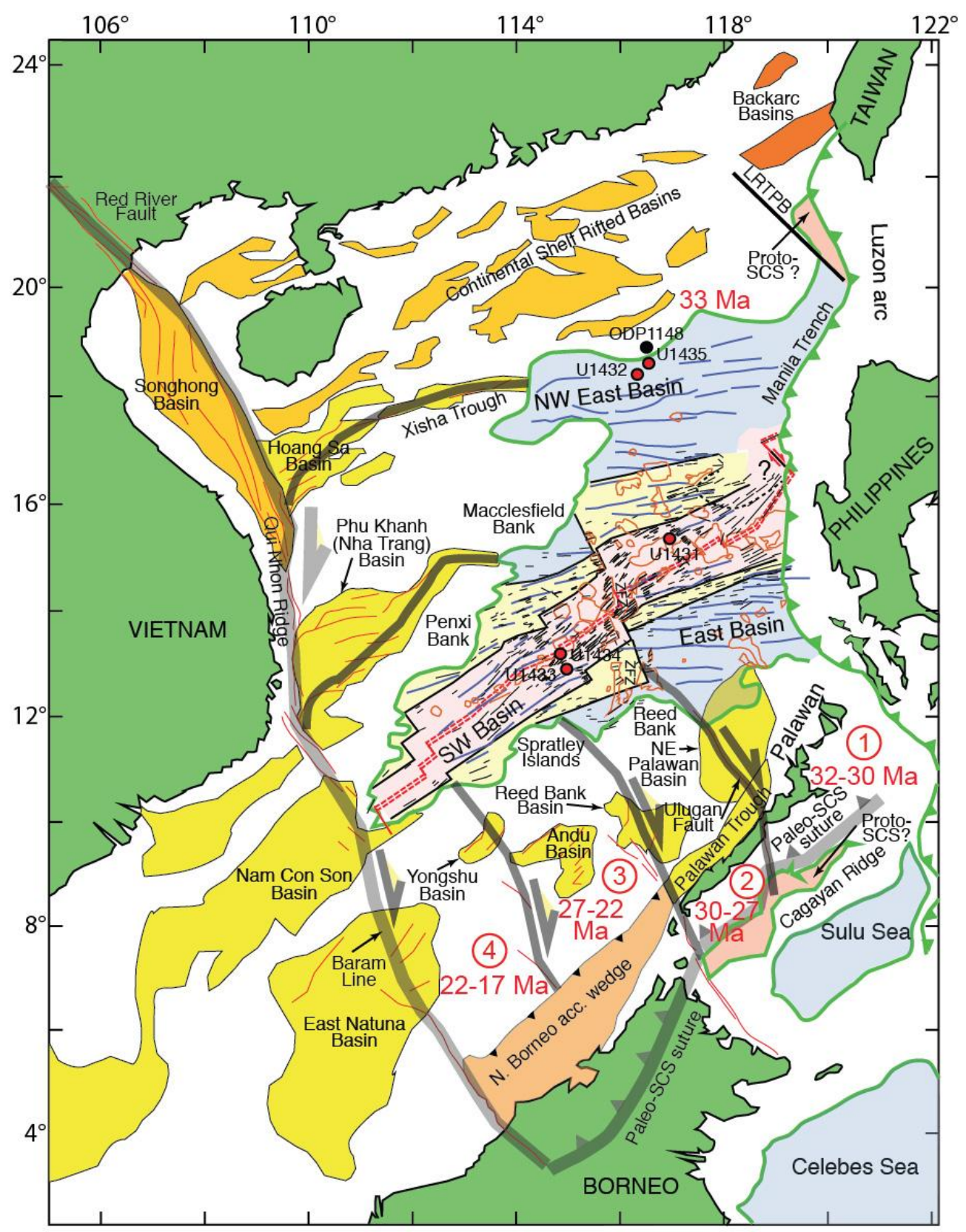

Figure 15: Structural map of the South China Sea (SCS) replaced in the general SE Asia background established from Pubellier et al. (2015). The paleo-suture of the proto-SCS (thick light grey line with triangles) is located south of Palawan and in north Borneo. The dark grey lines in the Xisha trough and Hoang Sa basin and possibly south of the Macclesfield bank and in the Phu Khanh basin are EU/SSCS tensional plate boundaries active during Early Oligocene. They follow rifted basins where normal faults (red lines) curve southward at the contact with the Qui Nhon ridge, showing that limited dextral motion occurred along the Qui Nhon ridge. From late Oligocene to middle Miocene, the western SSCS/EU plate boundary is connected to the subducting proto-SCS and jumped westward several times from the Ulugan fault to the western limit of the oceanic southwest sub-basin. Periods of ages given for each of the four segments of the southern margin are the periods during which such a segment moved southward along the fault located west of this segment. Note that the onset of oceanic crust for the conjugate segment of northern Palawan (Tainan segment) is $33 \mathrm{Ma}$ (IODP Preliminary Report, 2014) and is similar to the breakup unconformity onset in the NW Palawan basin. On the northern south China continental shelf, the Paleocene-Eocene rifted basins appear in light orange from the Luzon Ryukyu transform plate boundary (LRTPB) to the Songhong basin. East of the LRTPB, the continental shelf backarc basins appear in dark orange. Legend and colors in the SCS as in Figure 10. 


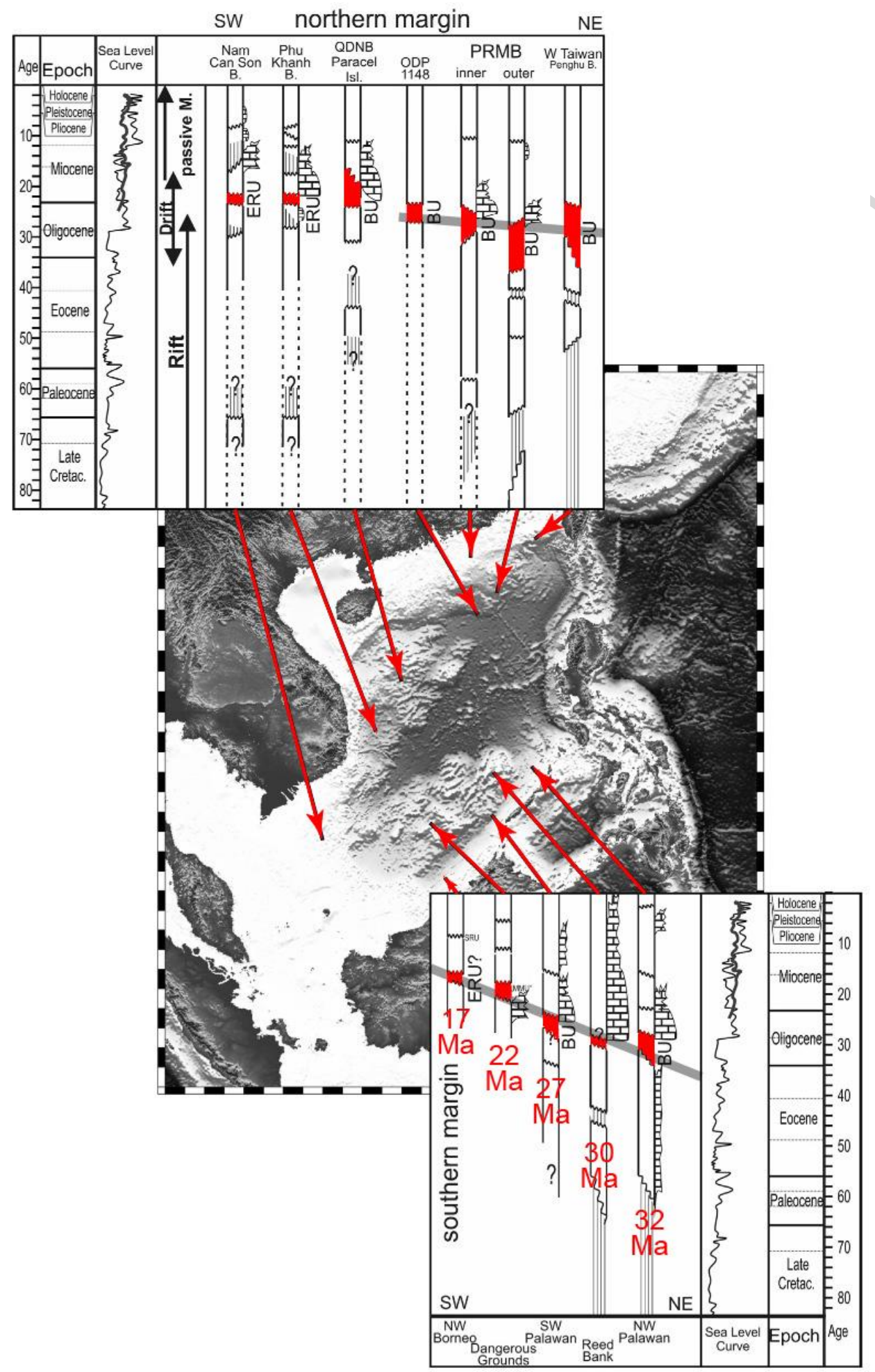

Figure 16: Breakup or end-rift unconformities (BU or ERU) around the South China Sea from different sources (modified from Franke (2014)). PRMB, Pearl River Mouth basin; QDNB, Qiongdongnan (Hoang Sa) basin. Sea level curves after Haq et al. (1987) and Yubo et al. (2011). Ages of the onset of BU or ERU are indicated in red under each column. Note the decreasing ages of BU or ERU from east to west along the southern SCS continental margin, which is coherent with the plate kinematic sketches of Figure 13. 